\title{
Membrane System for Recovery of Volatile Organic Compounds from Remediation Off-Gases
}

Phase I Topical Report

for the period

October 1996 - April 1997

prepared for

U.S. Department of Energy

Federal Energy Technology Center

3610 Collins Ferry Road

Morgantown, WV 26505

Contract No.: DE-AR21-96MC33081

prepared by

Membrane Technology and Research, Inc.

1360 Willow Road

Menlo Park, CA 94025

April 1997

Contributors:

J.G. Wijmans

S. Goakey

X. Wang

R.W. Baker

J.H. Kaschemekat 


\section{SUMMARY}

In situ vacuum extraction, air or steam sparging, and vitrification are widely used methods of remediating soil contaminated with volatile organic compounds (VOCs). All of these processes produce a VOC-laden air stream from which the VOC must be removed before the air can be discharged or recycled to the generating process. Treatment of these off-gases is often a major portion of the cost of the remediation project. Carbon adsorption and catalytic incineration, the most common methods of treating these gas streams, suffer from significant drawbacks.

Membrane Technology and Research, Inc. (MTR) proposes an alternative treatment technology based on permselective membranes that separate the organic components from the gas stream, producing a VOC-free air stream. The technology we propose to develop can be applied to off-gases produced by various remediation activities. The system will be skid-mounted and automatic for easy transportation and unattended operation. The system will remove the VOCs as a concentrated liquid phase and produce clean air (less than 10 ppmv VOC) for discharge or recycle and produce dischargeable water (less than 1 ppmw VOC).

This report contains the results obtained during Phase I of a two-phase project. In Phase I laboratory experiments were carried out to demonstrate the feasibility of the proposed approach. In the subsequent Phase II, a demonstration system is to be built and operated at two field sites. The work performed in Phase I demonstrated that

(1) membrane modules containing feed-side baffles have better VOC/air separation properties than conventional modules,

(2) hollow fiber contactors are very efficient stripping devices for the removal of VOC from water,

(3) the novel system design developed is capable of reducing the VOC concentration in remediation off-gas to $10 \mathrm{ppmv}$, while producing a concentrated VOC phase and dischargeable water containing less than 1 ppmw VOC, and

(4) the membrane system is competitive with carbon adsorption if the VOC concentration in the remediation off-gas is $100 \mathrm{ppmv}$ or higher.

A design was prepared for a demonstration system able to treat $100 \mathrm{scfm}$ off-gas, and two field sites have been identified. In the subsequent Phase II we propose to build the system and install it at the McClellan Air Force Base and the DOE Paducah site in Kentucky for field demonstrations. 
Table of Contents

SUMMARY $\mathrm{i}$

1. INTRODUCTION $\ldots \ldots \ldots \ldots \ldots \ldots \ldots \ldots \ldots \ldots \ldots \ldots \ldots \ldots \ldots$

2. BACKGROUND TO MEMBRANE GAS AND VAPOR PERMEATION . . . . . . 2

3. TECHNICAL APPROACH FOR REMEDIATION APPLICATIONS ....... 5

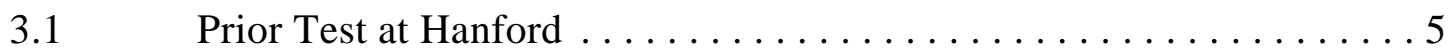

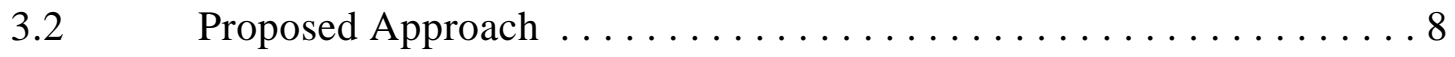

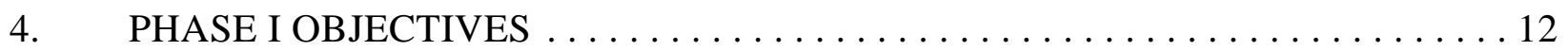

5. WATER SEPARATION SYSTEM TESTING $\ldots \ldots \ldots \ldots \ldots \ldots \ldots \ldots \ldots$

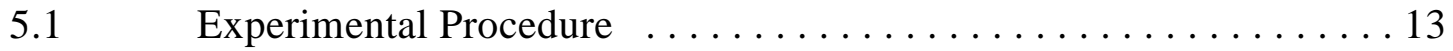

$5.2 \quad$ Performance of Hollow Fiber Contactor . . . . . . . . . . . . 14

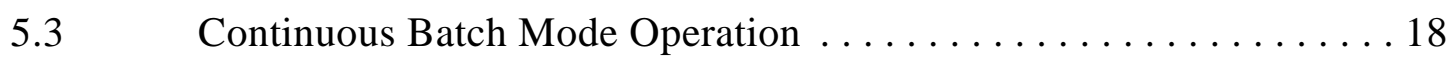

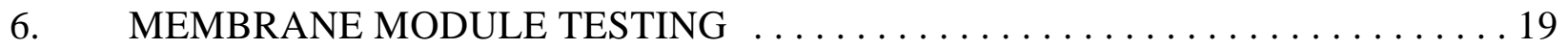

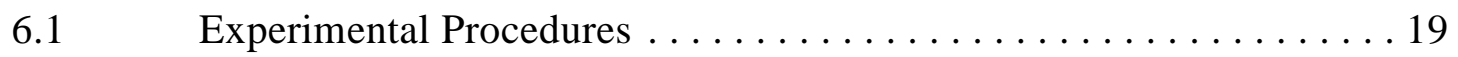

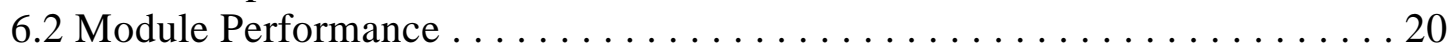

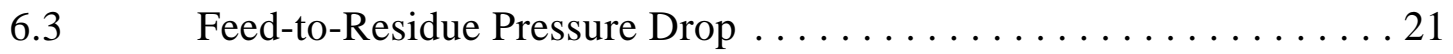

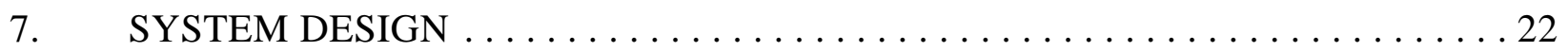

$7.1 \quad$ Selection of Configuration and Operating Conditions . . . . . . 23

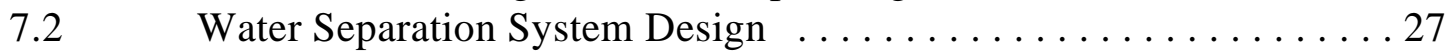

8. TECHNICAL AND ECONOMIC ANALYSIS $\ldots \ldots \ldots \ldots \ldots \ldots \ldots \ldots \ldots$

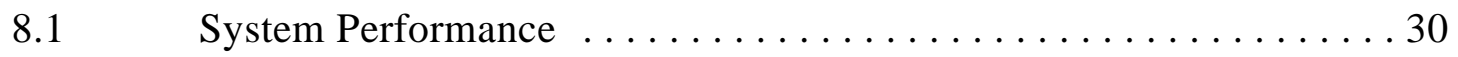

8.2 Membrane System Cost Estimate and Comparison with

Competing Technologies ........................... 34

8.3 Sequential Use of Membranes and Carbon Canisters . . . . . . . . 37

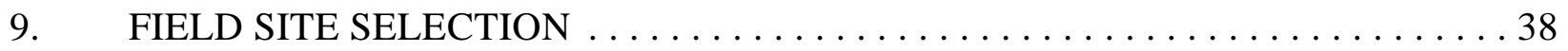

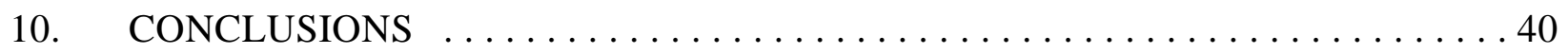

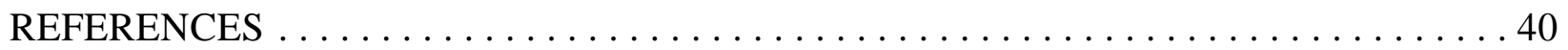




\section{List of Figures}

Figure 1. Schematic of an MTR composite membrane $\ldots \ldots \ldots \ldots \ldots \ldots \ldots \ldots$

Figure 2. Schematic of a spiral-wound membrane module $\ldots \ldots \ldots \ldots \ldots \ldots \ldots$

Figure 3. Photograph of system and performance data for carbon tetrachloride recovery by a membrane system tested at Hanford on a soil extraction vent gas stream . 6

Figure 4. Flow schematic of pilot-scale membrane system tested at the Hanford Nuclear

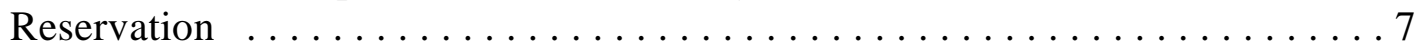

Figure 5. Flow schematic of proposed proof-of-concept membrane separation system ... 9

Figure 6. Unwound views showing gas flow path in (a) a conventional spiral-wound module with direct flow across the membrane surface and (b) a module with baffles to create a tortuous path for the feed $\ldots \ldots \ldots \ldots \ldots \ldots \ldots \ldots$

Figure 7. CFC-113/nitrogen selectivity as a function of flow rate for unbaffled and baffled

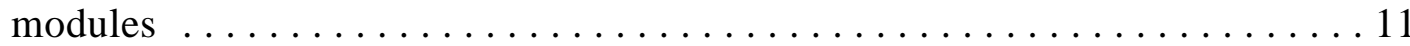

Figure 8 . A schematic of the laboratory water separation system $\ldots \ldots \ldots \ldots$

Figure 9. Removal of VOCs from feed by the membrane contactor in the base case

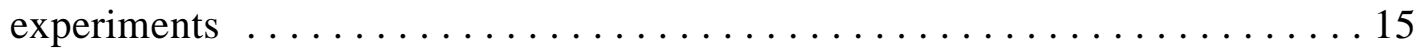

Figure 10. Removal of toluene from feed by the membrane contactor under different flow

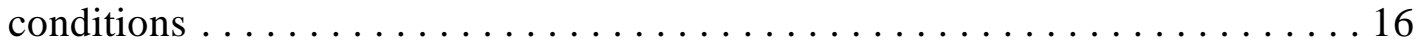

Figure 11. Removal of methylene chloride from feed by membrane contactor under

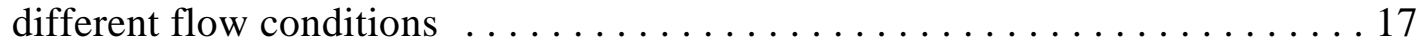

Figure 12. Removal of methylene chloride from water in a semi-continuous batch system

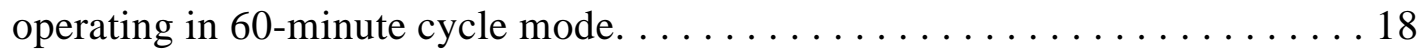

Figure 13. Removal of toluene from water in a semi-continuous batch system operating in 60 -minute cycle mode ......................... . . . . . . .

Figure 14. Effective selectivity for TCE over nitrogen of baffled and regular modules as a

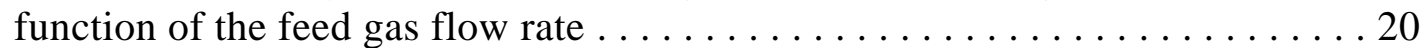

Figure 15. TCE removal achieved by three baffled modules in series as a function of the

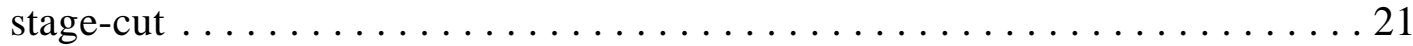




\section{List of Figures - Continued}

Figure 16. Feed-to-residue pressure drop observed for a baffled module and a regular module as a function of the feed gas flow rate $\ldots \ldots \ldots \ldots \ldots \ldots \ldots \ldots \ldots$

Figure 17. Schematic of membrane system for the removal of VOCs from remediation off-

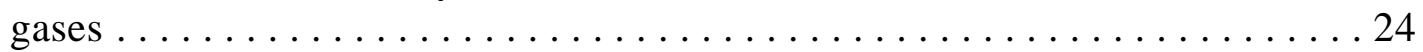

Figure 18. Schematic of membrane system for the removal of VOCs from remediation off-gases using a two-step configuration in the first membrane stage . . . . . 25

Figure 19. Membrane area and horsepower requirements calculated for the one-step (Figure 17) and two-step (Figure 18) configurations for different VOC removals . . . . 25

Figure 20. Membrane area and horsepower requirements calculated for the two-step configuration as a function of the Intermediate VOC Concentration between the

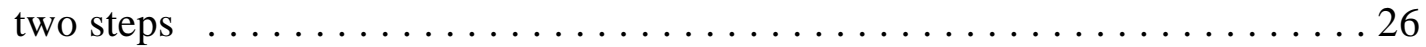

Figure 21. Membrane area and horsepower requirements calculated for the two-step configuration as a function of the permeate pressure of the first step (see

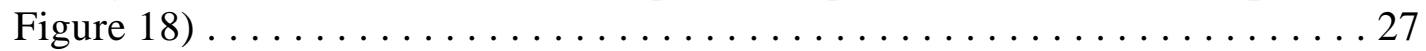

Figure 22. Schematic of the water separation system which removes VOCs from the condensate produced by the condenser in the first stage $\ldots \ldots \ldots \ldots \ldots 28$

Figure 23. Performance of the water separation system as predicted under varying

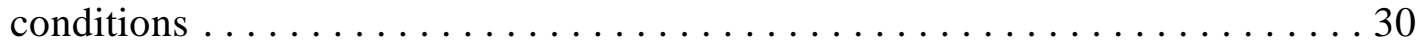

Figure 24. VOC vent concentration in vent as a function of the VOC feed concentration . 32

Figure 25. Membrane area and horsepower requirements calculated for the two-step configuration as a function of the VOC vent concentration . . . . . . . 33

Figure 26. System capacity as a function of the VOC vent concentration ......... 34

Figure 27. Monthly operation costs as a function of VOC concentration in a 100-scfm air stream for carbon systems and membrane systems $\ldots \ldots \ldots \ldots \ldots$

Figure 28. VOC concentration in the off-gas produced by a soil vacuum extraction remediation operation as a function of time $\ldots \ldots \ldots \ldots \ldots \ldots \ldots \ldots \ldots \ldots$ 


\section{List of Tables}

Table 1. MTR-135 Membrane Selectivity to Common Industrial Organic Vapors, Measured at Ambient Temperature .................. 5

Table 2. Characteristics of Screw and Liquid-Ring Compressors of Approximately 170 scfm Capacity ........................... 10

Table 3. Value of Henry's Law Coefficient $(\mathrm{H})$ and VOC Transfer Parameter $(\mathrm{K} \cdot \mathrm{A})$ for Each VOC ................................ 15

Table 4. Value of VOC Transfer Parameter $(\mathrm{K} \cdot \mathrm{A})$ at Different Experimental Conditions

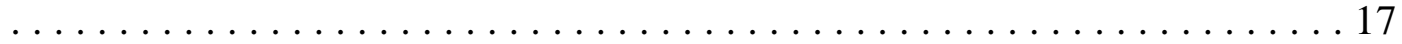

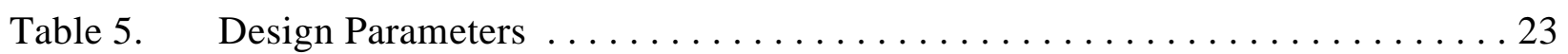

Table 6. Parameter Values Used to Predict Water Separation System Performance . . . 29

Table 7. Effect of VOC Volatility and VOC Mixture Composition on Vent

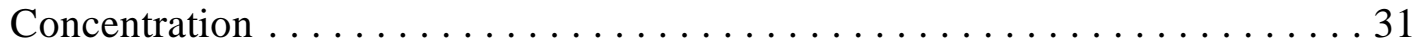

Table 8. Composition of Condensate Produced by the Condenser in the Second Stage

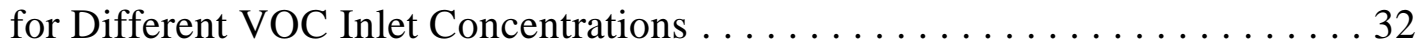

Table 9. Capital Cost Breakdown for Membrane System Treating $100 \mathrm{scfm}$ of Air

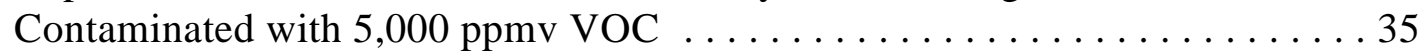

Table 10. Operating Cost Breakdown for Membrane System Treating $100 \mathrm{scfm}$ of Air

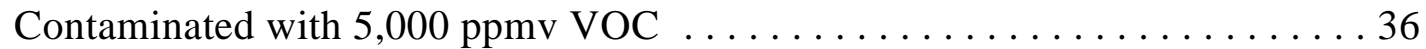

Table 11. Operating Costs for the Ownership and Rental Options as a Function of the VOC

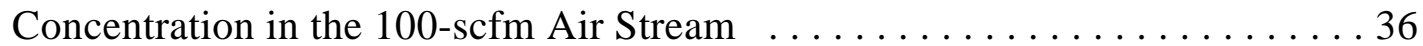




\section{INTRODUCTION}

In situ vacuum extraction, air or steam sparging, and vitrification are widely used methods of remediating soil contaminated with volatile organic compounds (VOCs). All of these processes produce a VOC-laden air stream from which the VOC must be removed before the air can be discharged or recycled to the generating process. Treatment of these off-gases is often a major portion of the cost of the remediation project. Carbon adsorption and catalytic incineration, the most common methods of treating these gas streams, suffer from significant drawbacks.

Membrane Technology and Research, Inc. (MTR) proposes an alternative treatment technology based on permselective membranes that separate the organic components from the gas stream, producing a VOC-free air stream. The technology we propose to develop can be applied to all of these off-gas streams and is not tied to a particular off-gas generating source. We propose to develop a completely self-contained system because remediation projects are frequently in remote locations, where access to trained operators and utilities is limited. The system will be a turnkey unit, skid-mounted and completely automatic, requiring electric power but no other utilities. The system will process the off-gas, producing a concentrated liquid VOC stream and a purified gas containing less than $10 \mathrm{ppm}$ VOC that can be discharged or recycled to the gas-generating process.

Removal of VOCs from air streams with membranes is a relatively new technology. To date, most membrane systems have been installed on process streams in the refining and petrochemical industries. The first demonstration plants were installed by MTR in 1990-91, with the first commercial plants being sold in 1992-93. Currently, more than 30 units are operating in the United States and overseas, all supplied by MTR. Off-gases produced in DOE remediation operations are much less concentrated in VOCs than the chemical plant streams treated by our membrane technology to date. However, a pilot test of a membrane system at the Hanford Nuclear Reservation on an off-gas stream containing 200-1,000 ppm carbon tetrachloride showed the overall feasibility of the process. The membrane system consistently achieved greater than 95\% VOC removal and produced dischargeable air containing less than $20 \mathrm{ppm}$ VOC. The test also showed that modifications to the system design are required to tailor the technology to this type of remediation to this application. In particular, the module design must be modified to improve the VOC/air separation. Also, the system design must be changed to allow operation with flammable VOCs and to remove water coextracted with the VOCs, to reduce the volume of hazardous waste requiring disposal.

This report covers the first phase of a two-phase project. The first phase involved the laboratory demonstration of the water separation section of the unit, the production and demonstration of new membrane modules to improve the separation, the design studies required for the demonstration system, and initial contacts with potential field sites. In the second phase, the demonstration system will be built and, after a short laboratory evaluation, will be tested at two field sites. 


\section{BACKGROUND TO MEMBRANE GAS AND VAPOR PERMEATION}

The separation of gases by permselective membranes has a long history dating back to the work of Thomas Graham. However, the first systematic studies with polymer membranes of the type used today did not begin until the 1940s, when van Amerongen, Barrer and others laid the foundation of modern theories of gas permeation. ${ }^{1-3}$ Progress has been made since that time, but our basic understanding of membrane science has not changed..$^{4-8}$ Although membranes with useful selectivities to commercially interesting gas mixtures were known by the 1960s, the membranes were too expensive and the permeation rates were too low for large-scale applications. Both of these problems were solved in the 1960s and early 1970s by the developers of reverse osmosis membranes, who were the first to make defect-free, high-flux asymmetric membranes and incorporate large surface areas of these membranes into modules., ${ }^{9,10}$ The technology to produce such membranes and modules is well developed at MTR.

A synthetic polymer membrane can separate the components of a gas or vapor mixture because the components permeate the membrane at different rates. The basic model of membrane transport continues to be the solution-diffusion model developed by van Amerongen, Barrer and others. ${ }^{1-3}$ In this model, it is assumed that gas at the high-pressure side of the membrane dissolves in the membrane material and diffuses down a concentration gradient to the low-pressure side of the membrane, where the gas is desorbed. It is also assumed that the gas phases on either side of the membrane are in thermodynamic equilibrium with their respective polymeric interfaces and that the interfacial sorption and desorption process is rapid compared with the rate of diffusion through the membrane. Thus, the rate-limiting step is diffusion through the polymer membrane, governed by Fick's law of diffusion. Fick's law leads to the equation

$$
J=\frac{D S \Delta p}{\ell}
$$

where $J$ is the membrane flux $\left[\mathrm{cm}^{3}(\mathrm{STP}) / \mathrm{cm}^{2} . \mathrm{s}\right], D$ is the diffusion coefficient of the gas in the membrane $\left[\mathrm{cm}^{2} . \mathrm{s}\right]$ and is a measure of the gas mobility, $S$ is the Henry's law sorption coefficient linking the concentration of the gas in the membrane material to the pressure in the adjacent gas $\left[\mathrm{cm}^{3}(\mathrm{STP}) / \mathrm{cm}^{3} \cdot \mathrm{cmHg}\right], \Delta p$ is the pressure difference across the membrane $[\mathrm{cmHg}]$, and $\ell$ is the membrane thickness (cm). Equation (1) can also be written

$$
J=\frac{P \Delta p}{\ell}
$$

where $P$ is the permeability, equal to the product $D S$, and is a measure of the rate at which a particular gas moves through a membrane of standard thickness $(1 \mathrm{~cm})$ under a standard pressure difference $(1 \mathrm{cmHg})$. The permeability unit, $1 \times 10^{-10} \mathrm{~cm}^{3}(\mathrm{STP}) \mathrm{cm} / \mathrm{cm}^{2} \cdot \mathrm{s} \cdot \mathrm{cmHg}$, is often called a Barrer, after R.M. Barrer, a pioneer in membrane permeation studies. ${ }^{2}$ 
The transport of any gaseous component through a membrane is characterized by a permeation flux, $Q\left[\mathrm{~cm}^{3}(\mathrm{STP}) / \mathrm{cm}^{2} \cdot \mathrm{s} \cdot \mathrm{cmHg}\right]$, defined as

$$
Q=\frac{P}{\ell}=\frac{J}{\Delta p}
$$

or

$$
J=Q \Delta p
$$

A measure of the ability of a membrane to separate two gases or vapors (1) and (2) is the selectivity, $\alpha$, defined as the ratio of their permeabilities:

$$
\alpha=\frac{P_{1}}{P_{2}}=\frac{D_{1} S_{1}}{D_{2} S_{2}}
$$

or, in terms of the individual overall normalized permeation fluxes,

$$
\alpha=\frac{Q_{1}}{Q_{2}}
$$

since the membrane thickness $\ell$ is constant. The intrinsic selectivity of a polymer material is established by measuring the permeabilities with pure gas or vapor samples, then calculating the ratio. The selectivity obtained in an actual separation process is determined by making permeation measurements with gas mixtures.

In glassy materials, the dominant feature in the selectivity is the ratio of the diffusion coefficients $D_{1} / D_{2}$, which is heavily dependent on the ratio of the molecular sizes. In rubbery materials, the dominant feature is the ratio of the sorption coefficients $S_{1} / S_{2}$, which reflects the ratio of the condensabilities of the two permeants. Rubbery membrane materials efficiently separate organic vapors, which have relatively large molecules but are easily condensed, from gases, which are smaller molecules but not easily condensed. MTR specializes in the separation of organic vapors from air and other gas streams and has considerable experience in the production of rubbery membranes.

The membranes developed by MTR for the separation of organic vapors from air are composite structures, as shown schematically in Figure 1. The tough, open, microporous layer provides strength and the ultrathin permselective coating is responsible for the separation properties. 


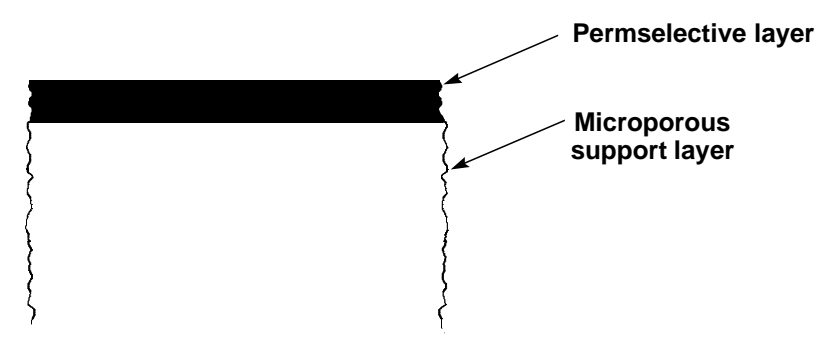

Figure 1. Schematic of an MTR composite membrane. Membrane in rolls 100-200 meters long and 10-40 $\mathrm{cm}$ wide are produced at MTR.

The composite membranes are incorporated into spiral-wound modules of the type illustrated schematically in Figure 2. Feed gas enters the module and flows between the membrane leaves. The component of the feed that is preferentially permeated by the membrane spirals inward to a central permeate collection pipe. The remainder of the feed flows across the membrane surface and exits as the residue. To meet the capacity and separation requirements of a particular application, modules are connected in serial or parallel flow arrangements.

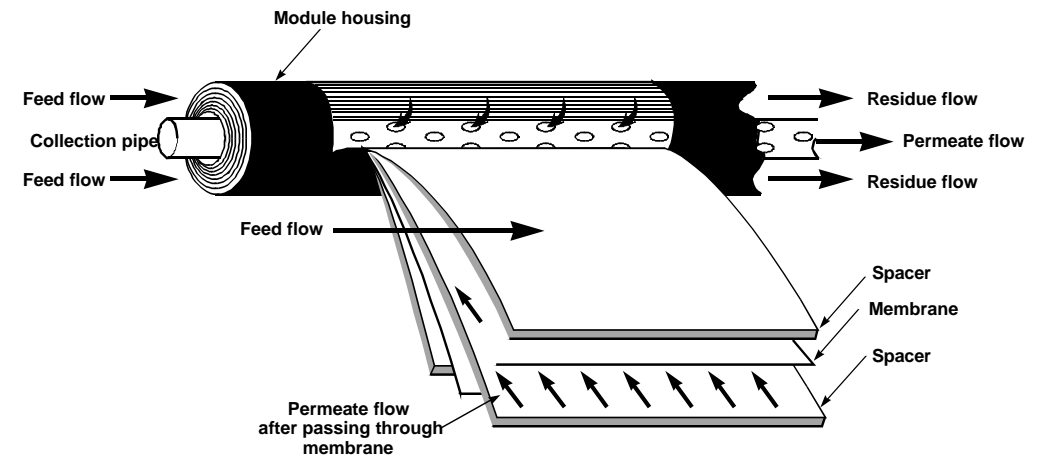

Figure 2. Schematic of a spiral-wound membrane module. The membrane area in MTR modules ranges from $0.3 \mathrm{~m}^{2}$ for laboratory modules to $6-15 \mathrm{~m}^{2}$ for industrial-scale modules.

Certain membrane materials, particularly hydrophobic rubbery polymers, possess an intrinsically high selectivity for organic vapors over air, allowing useful separations to be performed.

Our experience has shown that a membrane selectivity of greater than 10 is required if a membrane process is to be economically viable for the recovery of most industrial solvents. However, if the compound to be recovered is significantly more expensive than common industrial solvents, a membrane selectivity between 5 and 10 would be sufficient. The intrinsic selectivity of the MTR-135 membrane for a number of common industrial organic vapors is listed in Table 1. The effective selectivity achieved in membrane modules is typically lower because of additional mass transfer resistances outside the membrane itself. 
Table 1. MTR-135 Membrane Selectivity to Common Industrial Organic Vapors, Measured at Ambient Temperature.

\begin{tabular}{||l|c||}
\hline \multicolumn{1}{|c|}{ Vapor } & Membrane Selectivity \\
\hline Octane & $90-100$ \\
1,1,2-Trichloroethane & 60 \\
Isopentane & $30-60$ \\
Methylene chloride & 50 \\
CFC-11 $\left(\mathrm{CCl}_{3} \mathrm{~F}\right)$ & 45 \\
1,1,1-Trichloroethane & $30-40$ \\
Isobutane & $20-40$ \\
Tetrahydrofuran & $20-30$ \\
CFC-113 $\left(\mathrm{C}_{2} \mathrm{Cl}_{3} \mathrm{~F}_{3}\right)$ & 25 \\
Acetone & $15-25$ \\
CFC-114 $\left(\mathrm{C}_{2} \mathrm{Cl}_{2} \mathrm{~F}_{4}\right)$ & 10 \\
\hline
\end{tabular}

\section{TECHNICAL APPROACH FOR REMEDIATION APPLICATIONS}

\subsection{Prior Test at Hanford}

Off-gases produced in DOE remediation operations are much less concentrated in VOCs than the chemical plant streams treated by our membrane technology to date. However, we performed a successful pilot test of a membrane system on this type of gas stream at the Hanford Nuclear Reservation in conjunction with Westinghouse Corporation. ${ }^{11-12}$ The target off-gas was air containing carbon tetrachloride produced by in-situ vacuum extraction of contaminated soil. The gas was saturated with water and contained 200-1,000 ppm carbon tetrachloride. The membrane system consistently achieved greater than 95\% VOC removal, producing dischargeable air containing less than $20 \mathrm{ppm}$ VOC. A photograph of the unit ready for shipping to the site, together with a performance curve obtained during the test are shown in Figure 3. 

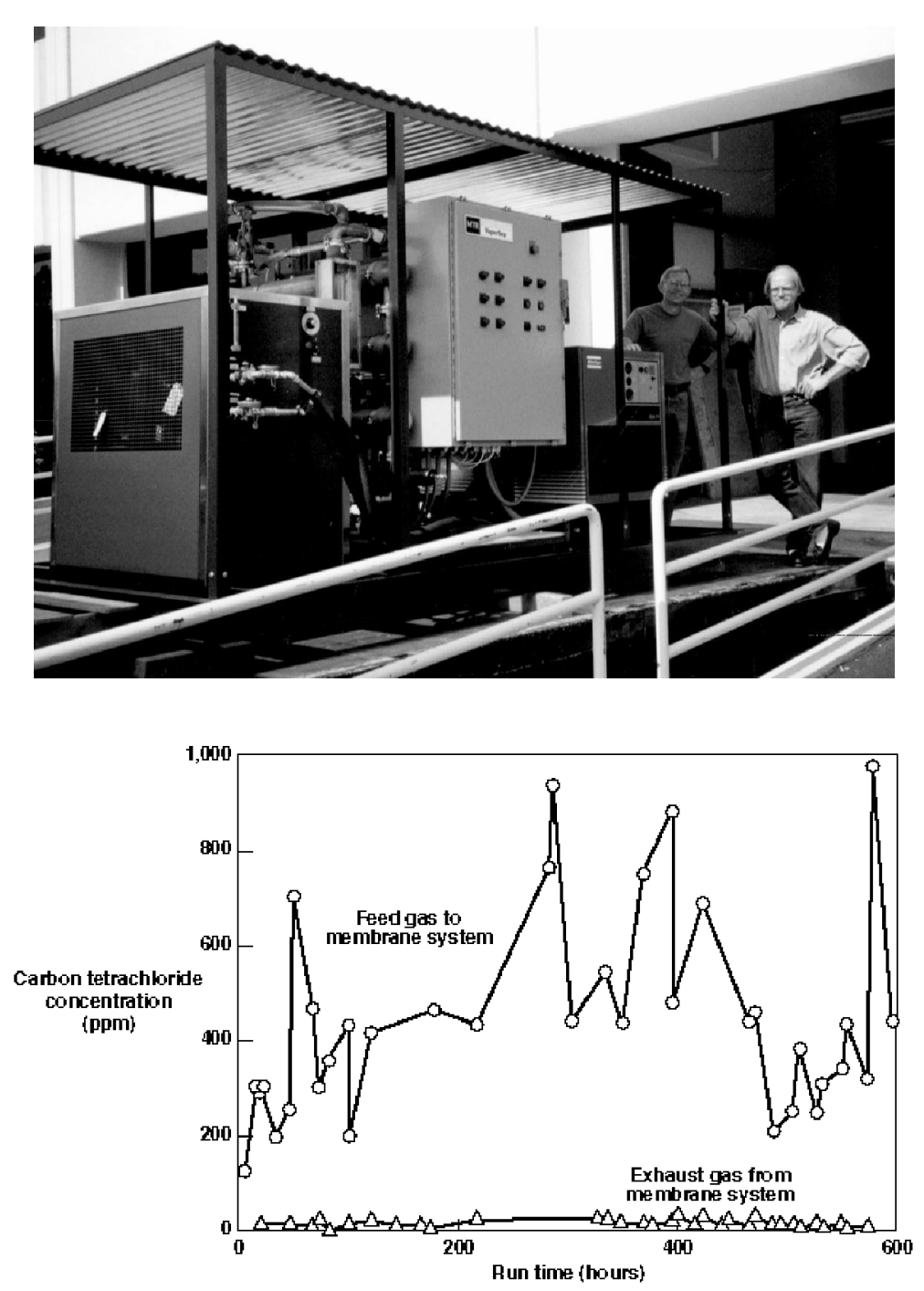

Figure 3. Photograph of system and performance data for carbon tetrachloride recovery by a membrane system tested at Hanford on a soil extraction vent gas stream. The 30 -scfm system provided the target $>95 \%$ VOC removal and concentrated the carbon tetrachloride into a condensed liquid that could be drummed and shipped for off-site disposal. $^{11}$

The design of the membrane system used at Hanford is shown in Figure 4. The VOCladen feed air is compressed to 150 psia. On cooling, a portion of the VOC condenses; the remaining gas then contacts one side of a membrane that is permeable to organic vapors but relatively permeable to air. A purified air stream is removed as the residue gas; the VOC-enriched permeate is returned to the front end of the compressor for recycling through the unit. 


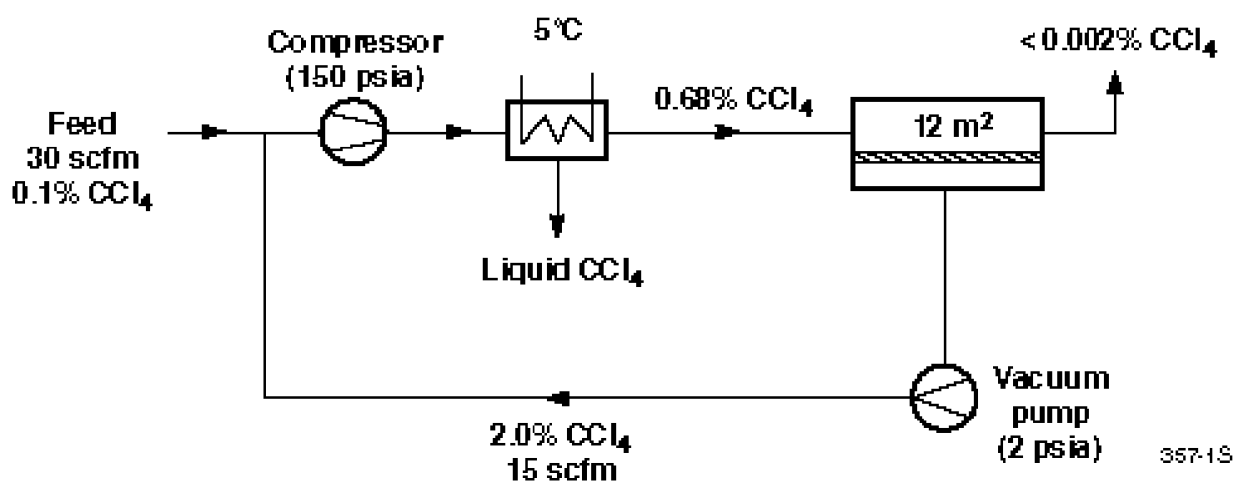

Figure 4. Flow schematic of pilot-scale membrane system tested at the Hanford Nuclear Reservation. The feed gas contained up to $1,000 \mathrm{ppm}$ carbon tetrachloride. The membrane unit separated this gas into a residue stream containing $<20 \mathrm{ppm}$ carbon tetrachloride that was vented and a permeate stream enriched in carbon tetrachloride that was remixed with the feed gas. The carbon tetrachloride builds up in this recycle loop until it begins to condense in the cooled condenser.

The Hanford pilot test demonstrated the overall feasibility of applying membrane vapor separation to VOC-laden off-gas from soil remediation, but raised a number of issues. The objective of the current project is to address the following issues:

(1) The off-gas treated by the unit was saturated with water vapor and contained approximately 10-20 times as much water vapor as VOC. Because the system removed both water vapor and organic vapors, the condensed VOC liquid was heavily contaminated with water. The membrane unit design being developed in this project has been modified to separate the condensed water vapor from the condensed VOC, thereby reducing the volume of hazardous waste requiring disposal.

(2) The off-gas produced at many DOE sites contains flammable VOCs such as hydrocarbon fuel vapors and aromatic hydrocarbons. A widely applicable treatment technology must be able to handle off-gas containing these VOCs. The recycle design shown in Figure 4 and tested at Hanford cannot treat such streams because of the potential explosion hazard caused by flammable vapors concentrating in the membrane recycle loop. An alternative design, suitable for operation with flammable feed gas, is being developed in this project.

(3) The system must be designed to meet the special needs of DOE remediation operations, including the requirements that:

- The system is rugged, operator-free, and low maintenance and requires electricity but no other utilities.

- The system is self-contained, turnkey and skid-mounted and is transportable by truck. 
- The system requires minimal site preparation.

- The system can be unloaded and assembled quickly ( less than a day) and easily (using only a fork lift and simple hand tools). Decontamination and disassembly should be just as easy.

- The system can safely handle off-gases containing a wide range of VOCs, flammable and nonflammable, chlorinated and non-chlorinated, varying in concentration from a few hundred ppmv to several thousand ppmv.

- The final off-gas discharged after treatment always contains less than 10 ppmv VOC.

\subsection{Proposed Approach}

A simplified schematic of the proposed system is shown in Figure 5. This unit incorporates the new features suggested by our previous experience from the Hanford test and our current understanding of DOE's needs. As can be seen from Figure 5, the off-gas containing water vapor and VOCs is compressed to 190 psia in a standard air compressor. The compressor after-cooler condenses out most of the water vapor and some of the VOC. A small air stripper removes the VOC from the condensed water so that the water can be discharged. The air leaving the aftercooler enters a set of membrane modules which contain a membrane that is much more permeable to VOCs than to air. The VOCs and some of the air permeate the membrane, thereby producing a nonpermeated stream which is depleted of the VOCs to concentration levels of 10 ppmv or less. The VOC-enriched permeate stream is recompressed in a liquid-ring vacuum pump. The air exhaust from the air stripper is sent to this vacuum pump as well. The vacuum pump compresses the air to about 820 psia, after which the VOC is condensed in a heat exchanger. The air leaving the heat exchanger still contains an appreciable amount of VOC, most of which is removed in a second membrane stage prior to the inlet of the system. The VOC-enriched permeate is returned to the vacuum pump, thereby creating a concentration loop for the VOCs that facilitates condensation of VOCs in the heat exchanger. 


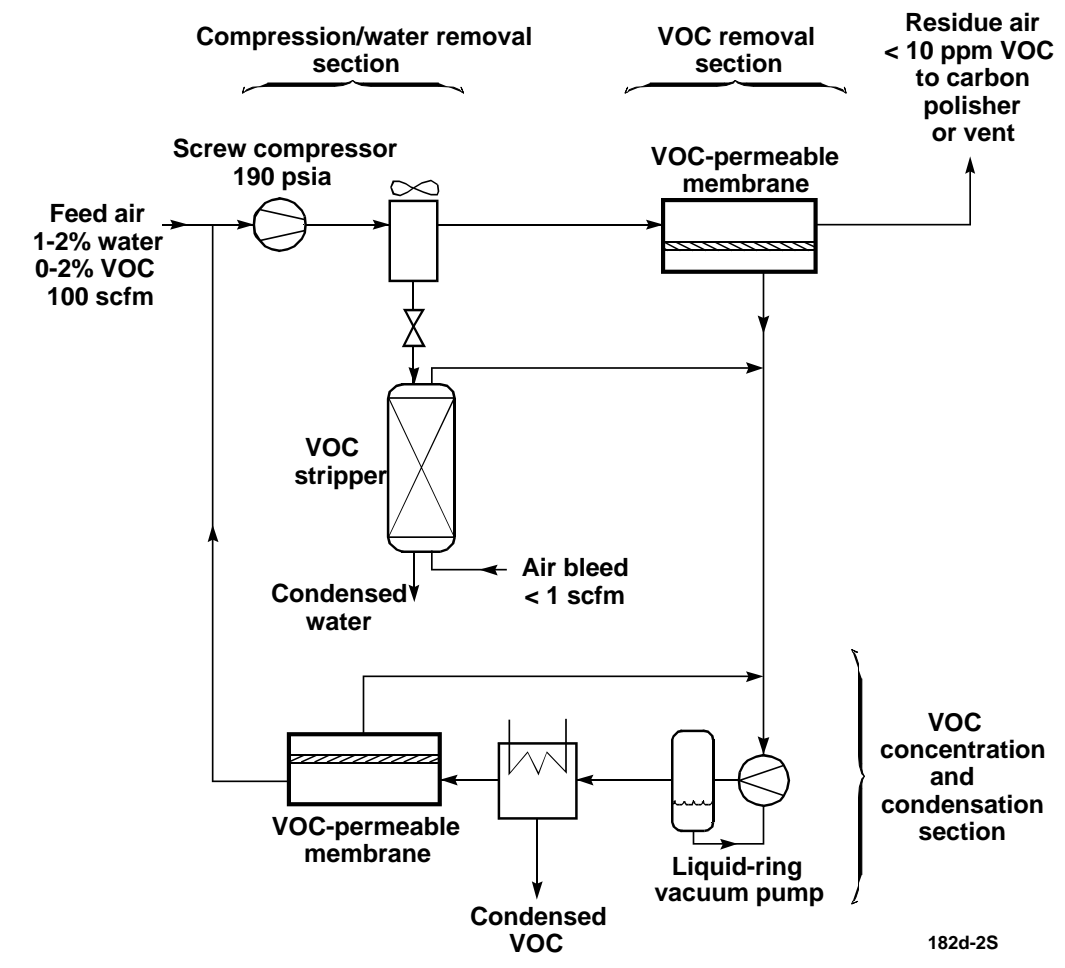

Figure 5. Flow schematic of proposed proof-of-concept membrane separation system. This unit separates the bulk of the water from the VOC and can be operated with flammable and nonflammable vapors.

To be widely used by DOE, the off-gas treatment process must be able to treat a wide variety of organic vapor mixtures, both flammable and nonflammable, in the concentration range 0-2 vol\%. The need to process flammable gas mixtures impacts the choice of the main compressor, the most expensive and important piece of rotating equipment in a membrane vapor separation system. The Hanford pilot trial demonstrated that a low-cost screw compressor could be used with vapor mixtures in the target range. However, a screw compressor cannot be used with flammable vapor mixtures in a system of the Hanford design because of build-up of organic vapors in the recirculation loop. As shown in Figure 4, the vapor concentration in the recirculation loop can easily be 5-10 times the vapor concentration in the incoming feed gas. Normally, this high concentration of feed vapor would be compressed by a liquid-ring compressor. Liquid-ring compressors are rugged, reliable, and intrinsically safe even when operated with flammable organic vapor mixtures, but they are three to five times more expensive than screw compressors of the same capacity. Also, because they are less efficient, liquid-ring compressors use more than twice as much power as screw compressors. This excess power is lost as waste heat; consequently, liquid-ring compressors need an external supply of cooling water, whereas screw compressors are normally air cooled. A comparison of screw and liquid-ring compressors of approximately the same capacity is given in Table 2. 
Table 2. Characteristics of Screw and Liquid-Ring Compressors of Approximately $170 \mathrm{scfm}$ Capacity.

\begin{tabular}{||l|c|c||}
\hline \multicolumn{1}{|c|}{ Characteristic } & $\begin{array}{c}\text { Screw Compressor } \\
\text { (Kaiser or Equivalent) }\end{array}$ & $\begin{array}{c}\text { Liquid-Ring Compressor } \\
\text { (Sihi or Equivalent) }\end{array}$ \\
\hline Maximum Pressure & $190 \mathrm{psia}$ & $115 \mathrm{psia}$ \\
Power Required & $50 \mathrm{hp}$ & $100 \mathrm{hp}$ \\
Cooling Method & Air & $12 \mathrm{gal} / \mathrm{min}$ water \\
\hline
\end{tabular}

As Table 2 shows, the advantages offered by a screw compressor are compelling. We have, therefore, modified the Hanford design to ensure that the main compressor always operates below $50 \%$ of the lower explosion limit (LEL) allowing a screw compressor to be used. This new design incorporates two sets of membrane modules, as shown in Figure 5. The first set of modules (the VOC removal section in Figure 5), separates the organic vapors from the feed gas, producing dischargeable air and a low-pressure permeate enriched five- to six-fold over the feed. This gas is then concentrated to the point of condensation in a secondary recycle loop (the VOC concentration and condensation section in Figure 5). Because the organic vapor concentration may enter the explosive range in this loop, a liquid-ring vacuum pump must be used. However, the volume of gas to be treated is now only $20 \%$ of the feed gas, so the size of this unit is manageable, and the cooling requirements of the vacuum pump are small enough that cooling by a built-in chiller is sufficient.

The second new feature incorporated in the redesigned system is our recently developed high-turbulence membrane module. A problem associated with the conventional spiral-wound module design when used with high-flux, highly selective membranes is concentration polarization in the boundary layer next to the membrane surface. Formation of a boundary layer is a normal result of fluid flow in a restricted channel. In a module with a highly selective membrane, the concentration of the permeating vapor decreases rapidly in the boundary layer. The boundary layer then acts as an additional resistance to permeation. As a result, the membrane selectivity obtained in membrane modules is often lower by a factor of two or more than the selectivity measured with membrane stamps in laboratory test cells. Improved flow patterns in modules will provide significant improvements in system performance by reducing boundary layer thickness.

Recently, we have developed modified modules incorporating gas flow baffles in the feedside spacer of the spiral-wound module. The gas flow pattern in a conventional module and in a modified module are compared in Figure 6. In the conventional module shown in Figure 6(a), the gas flows directly across the membrane surface. In the modified module illustrated in Figure 6(b), incorporation of seven baffles increases the average gas velocity in the module sevenfold by creating a tortuous path for the gas. 

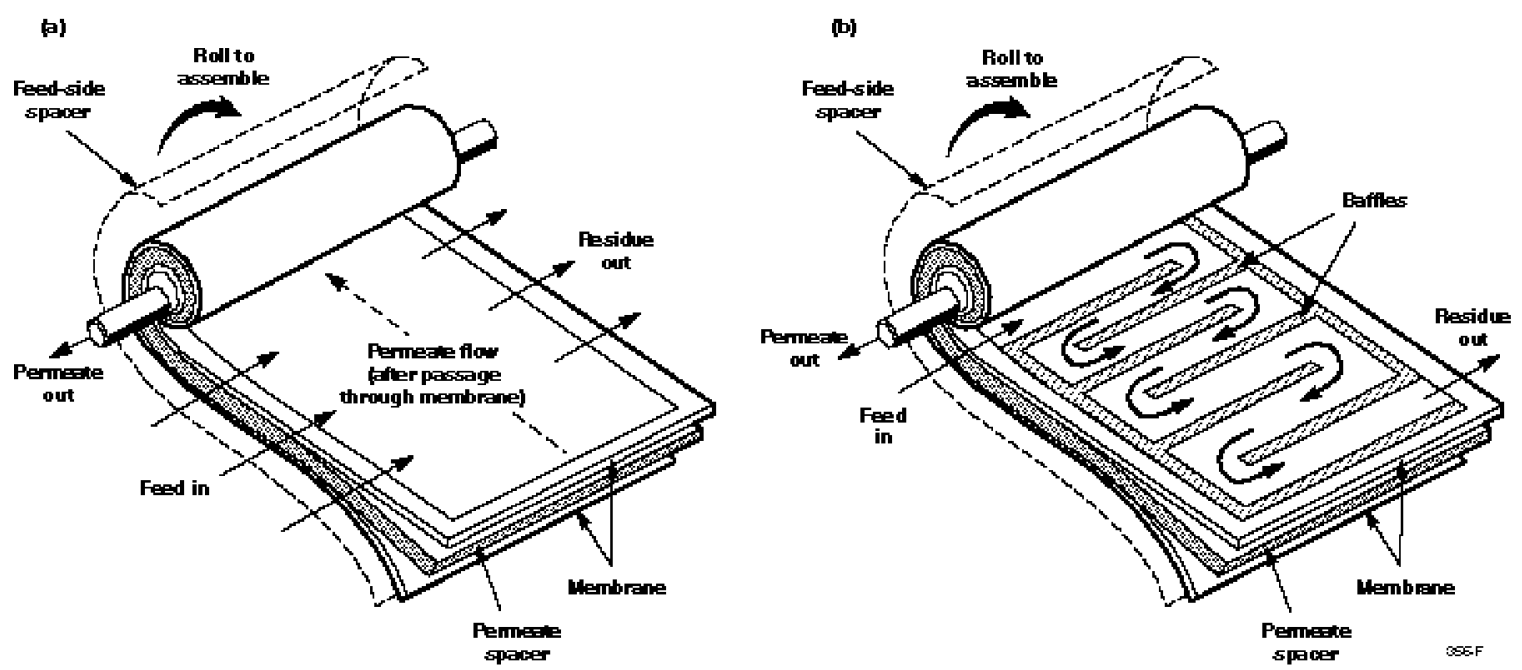

Figure 6. Unwound views showing gas flow path in (a) a conventional spiral-wound module with direct flow across the membrane surface and (b) a module with baffles to create a tortuous path for the feed. The gas flow baffles increase the path length for the gas through the module, increasing the average gas velocity and eliminating flow stagnation.

Data obtained with prototype modules of this type show clearly that these modules have significantly better selectivities than the unbaffled modules. Figure 7 compares the selectivity of modules with no baffles and with three and five parallel baffles as a function of the feed flow rate for an air/CFC-113 mixture. The dramatic increase in selectivity as baffles are added to the feed channel shows that the introduction of baffles diminishes the negative influence of concentration polarization and improves the module performance.

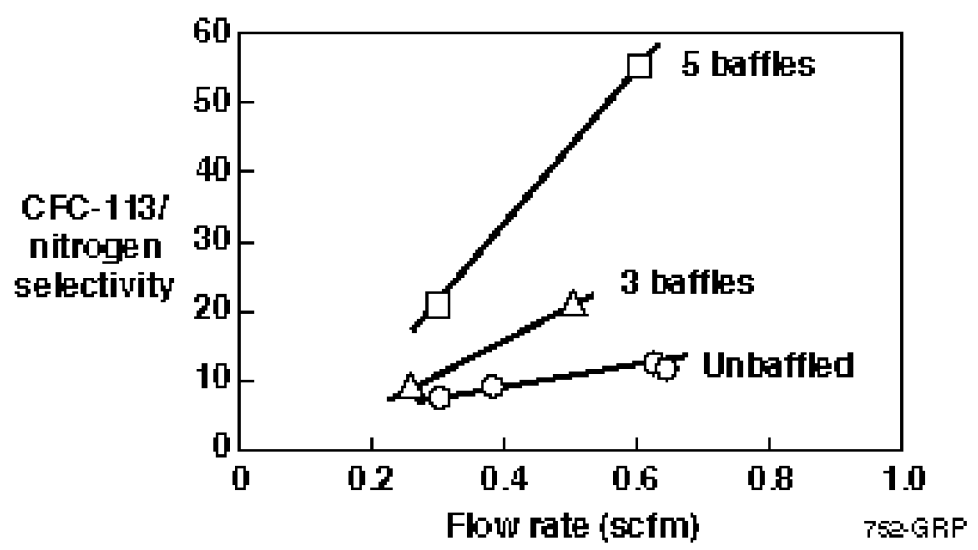

Figure 7. CFC-113/nitrogen selectivity as a function of flow rate for unbaffled and baffled modules. With a larger number of baffles, the module performance improves. 
The final innovation in the new unit is the addition of an after-cooler to the main compressor and a small air stripper to separate condensed water from condensed VOCs. Most of the water contained in the incoming air feed can then be discharged separately to the municipal sewer, and only the condensed VOC fraction needs to be treated as a hazardous waste. This waste-volume reduction will provide significant cost savings.

The temperature of compressed gas leaving the main compressor in Figure 5 is 100$120^{\circ} \mathrm{C}$. On cooling this gas to $40-60^{\circ} \mathrm{C}$ in a fan-cooled after-cooler, approximately $90 \%$ of the water vapor in the original feed will condense. This liquid water may also contain a small amount of dissolved VOCs, depending on the type and concentration of the VOC in the feed. A very small air stripper can be used to remove VOC from this water. The bleed air from the stripper, which contains the VOCs removed from the water, will be sent to the VOC concentration and condensation loop.

\section{PHASE I OBJECTIVES}

The overall objective of the complete project is to demonstrate the technical and economic feasibility of using a membrane-based treatment system for off-gas from a range of remediation operations. To achieve this objective we will design, construct, and evaluate a proof-of-concept membrane system of the new design able to treat $100 \mathrm{scfm}$ of off-gas. This unit will be tested at two field sites producing VOC-containing streams.

The specific objectives of the Phase I project were to:

1. Demonstrate in the laboratory the effectiveness of the water separation step.

2. Demonstrate in the laboratory the effectiveness of baffled modules.

3. Prepare a design for the system to be constructed in Phase II of the program, and evaluate possible field sites.

4. Perform a preliminary technical and economic analysis.

\section{WATER SEPARATION SYSTEM TESTING}

The approach we investigated is the use of an air stripper to remove VOCs from the aqueous condensate and to send the VOC-depleted air to the VOC condensation stage of the membrane system, as shown in Figure 5. Two different types of air stripper can be used:

(2) a hollow fiber membrane contactor. 
Both types of air strippers were purchased for the Phase I project, but the results presented here were all obtained with the membrane contactor, because the packed bed column showed very poor water flow distribution at the low water feed flow rates characteristic of the present application. The manufacturer modified the column to improve the flow distribution, but this modified column was not available in time to allow testing during Phase I.

However, the membrane contactor operated satisfactorily, and we were able to demonstrate removals in excess of $99 \%$ for methylene chloride, toluene and trichloroethylene. The membrane contactor is very well suited for the current low-flow-rate application because the exchange area between the water phase and the air phase is created by the fiber surfaces, rather than by the water flow pattern, as for the packed bed column. Another advantage of the membrane contactor is that the water phase can be at a higher pressure than the air phase (the fibers do not allow the passage of bulk water). This is a very useful characteristic for the present application, in which the air is pulled through the contactor by a vacuum pump.

\subsection{Experimental Procedure}

A simplified schematic of the laboratory testing system used to evaluate the performance of the membrane contactor is shown in Figure 8. The membrane contactor we used is a 2.5-inchdiameter $\times 8$-inch-long Liqui-Cel hollow fiber contactor, which is the smallest size available from the manufacturer Hoechst (Charlotte, NC). A small pump recirculates 3.5 gallon of VOC/water feed mixture from the feed tank through the contactor. The compressed air used as the stripping gas flows at essentially atmospheric pressure through the contactor counter-current to the liquid feed.

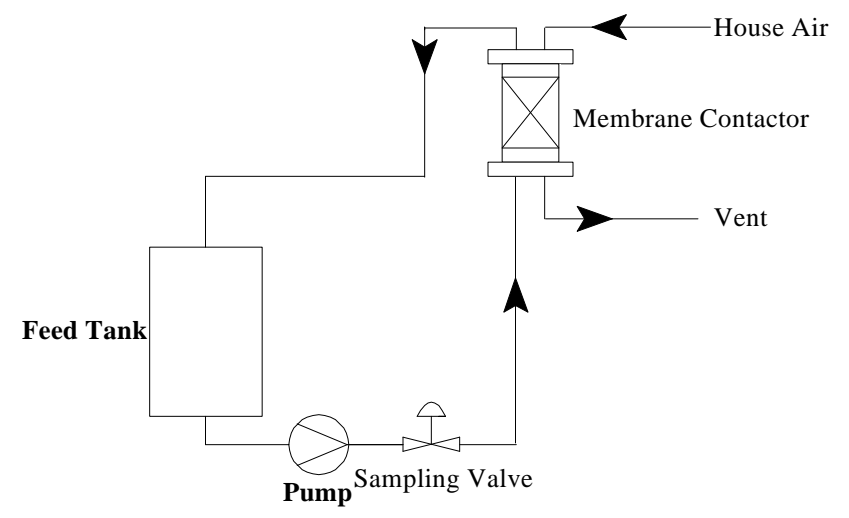

Figure 8. A schematic of the laboratory water separation system. A 3.5-gallon volume of a VOC/water mixture is circulated through the membrane contactor. Air flows through the contactor in a counter-current mode.

As the water passes through the contactor, VOC is transferred from the water phase to the air phase. The driving force for this transport is the difference in VOC partial vapor pressure between the water and air phases. Assuming that the partial pressure of VOC in the air stream is 
small compared to the equilibrium VOC partial vapor pressure of the water phase, the removal of VOC mirrors a first order reaction and can be expressed as:

$$
c_{\text {out }}=c_{\text {in }} \cdot \exp (-k \cdot A / Q)
$$

where $c_{\text {out }}$ and $c_{\text {in }}$ are the VOC concentration in the outlet and inlet water streams (ppmw), $k$ is the mass transfer coefficient $(\mathrm{cm} / \mathrm{s}), A$ is the total exchange area $\left(\mathrm{cm}^{2}\right)$ and $Q$ is the water recirculation flow rate $\left(\mathrm{cm}^{3} / \mathrm{s}\right)$. For the average VOC flux

$$
J_{\text {average }}=\frac{c_{\text {in }} \cdot Q}{A}[1-\exp (-k \cdot A / Q)]
$$

The concentration, $c_{i n}$, is a function of time because the system operates in a batch mode. The mass balance for the batch volume, $V$, that is recirculated through the contactor at the flow rate $Q$, is expressed as

$$
\begin{aligned}
V \cdot d c / d t & =-J_{\text {average }} \cdot A \\
& =-c_{\text {in }} \cdot Q \cdot(1-\exp (-k \cdot A / Q))
\end{aligned}
$$

which, after integration, yields

$$
c_{t}=c_{o} \cdot \exp [-Q \cdot t / V \cdot(1-\exp -k \cdot A / Q)]
$$

By measuring the concentration, $c$, as a function of time, equation (10) can be used to determine the value of the parameter $K \cdot A$, which is the product of the mass transfer coefficient and the exchange area in the contactor (the exact exchange area of the contactor is not known). This parameter is named the "VOC transfer parameter" in this report.

\subsection{Performance of Hollow Fiber Contactor}

In the base-case experiments, the VOC solution was circulated through the contactor at a water feed flow rate of 0.55 gallons per minute $(\mathrm{gpm})$ and the air flow rate was 50 standard cubic feet per hour (scfh). Three different VOCs were used: trichloroethylene (TCE), methylene chloride and toluene. Figure 9 shows the change in VOC concentration with time. In all three experiments, the VOC concentration in the water decreases exponentially with time, and the VOC concentrations drop by two decades in 60 minutes. 


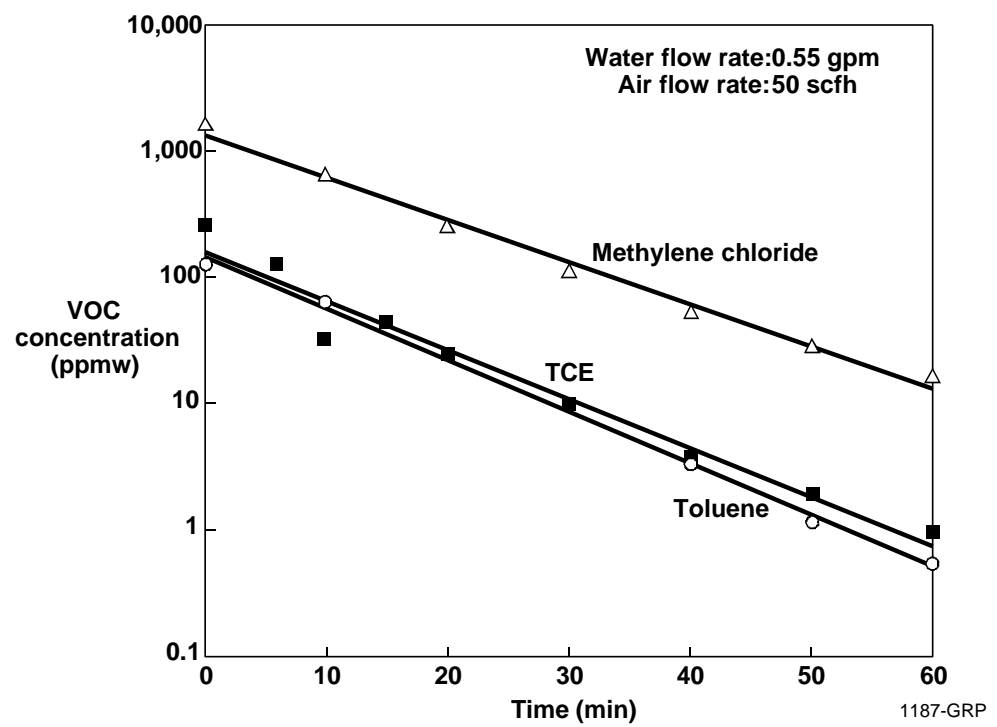

Figure 9. Removal of VOCs from feed by the membrane contactor in the base case experiments. VOC/water flow: $0.55 \mathrm{gpm}$; air flow: $50 \mathrm{scfh}$.

The VOC transfer parameter $K \cdot A$ can be calculated from the following version of equation (10)

$$
K \cdot A=-Q \ln \left[1+\frac{V}{Q \cdot t} \ln \left(\frac{c_{t}}{c_{o}}\right)\right]
$$

Table 3 shows that the $K \cdot A$ parameter is the highest for trichloroethylene and the lowest for methylene chloride. This was expected because TCE has the highest Henry's law coefficient and methylene chloride has the lowest. The Henry's law coefficient is an indicator of how well a VOC can be stripped from water.

Table 3. Value of Henry's Law Coefficient $(\mathrm{H})$ and VOC Transfer Parameter $(\mathrm{K} \cdot \mathrm{A})$ for Each VOC. Feed flow rate: $0.55 \mathrm{gpm}$; air flow rate: $50 \mathrm{scfh}$.

\begin{tabular}{||c|c|c||}
\hline VOC & $\mathrm{H}(\mathrm{atm} / \mathrm{mol})$ & $\mathrm{K} \cdot \mathrm{A}(\mathrm{gpm})$ \\
\hline TCE & 640 & 0.49 \\
\hline Toluene & 417 & 0.42 \\
\hline Methylene Chloride & 138 & 0.38 \\
\hline
\end{tabular}

To provide useful information for future system design, we performed additional experiments with methylene chloride and toluene in which the water flow rate and the air flow 
rate were varied. Figure 10 shows the removal of toluene in the feed over time under different flow conditions. By 
decreasing the water flow rate from $0.55 \mathrm{gpm}$ to $0.22 \mathrm{gpm}$, the toluene removal in one hour dropped from $99.5 \%$ to $76 \%$. By decreasing the air flow from $50 \mathrm{scfh}$ to $25 \mathrm{scfh}$, the toluene removal in one hour dropped only slightly, from $99.5 \%$ to $99.3 \%$.

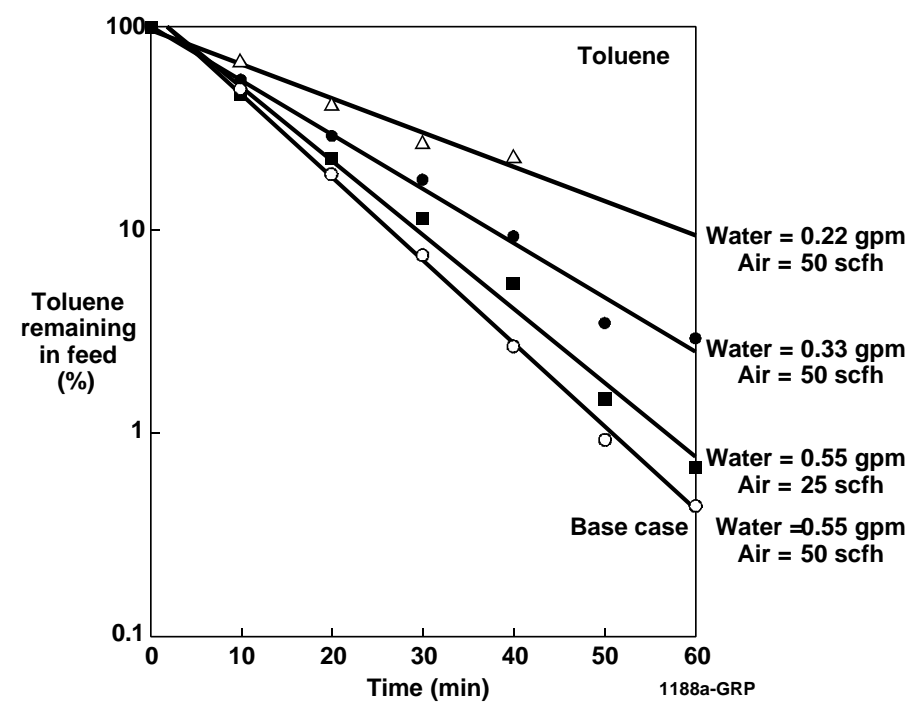

Figure 1. Removal of toluene from feed by the membrane contactor under different flow conditions.

The reduction in VOC removal with a decrease in the water recirculation flow rate, $Q$, is predicted by equation (10), but equation (10) predicts no reduction in VOC removal as the air flow rate is reduced. The latter prediction is a direct consequence of the assumption made in equation (8) that the partial pressure of VOC in the air stream can be ignored. As is clear from Figure 10, this is an acceptable assumption for the toluene experiments, since a twofold reduction in air flow rate did not significantly change the toluene removal.

Figure 11 shows the removal of methylene chloride as a function of time under different flow conditions. The removal decreases sharply as the water recirculation flow rate, $Q$, is reduced from $0.55 \mathrm{gpm}$ to $0.22 \mathrm{gpm}$, as is the case for toluene. In contrast to toluene, however, is the significant decrease in methylene chloride removal as the air flow rate is reduced from $50 \mathrm{scfh}$ to $25 \mathrm{scfh}$. This means that for methylene chloride the partial pressure in the air stream cannot be ignored. Methylene chloride has the lowest Henry's law coefficient of the three VOCs studied, that is, that the partial vapor pressure of a VOC above an aqueous VOC mixture is lowest for methylene chloride. Thus, for methylene chloride, the impact of its partial pressure in the air stream will be more significant on the stripping driving force than for toluene and TCE. 


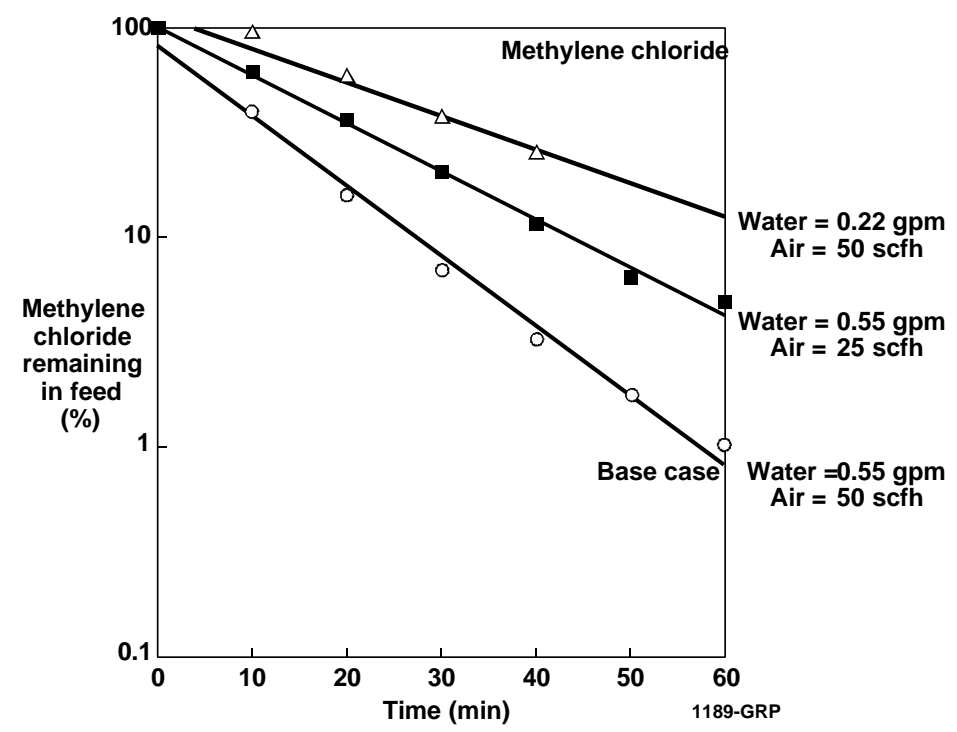

Figure 2. Removal of methylene chloride from feed by membrane contactor under different flow conditions.

For both toluene and methylene chloride, the parameter $K \cdot A$ decreases with decreasing water flow rate. This means that a liquid-phase boundary layer is present, which presents a resistance to mass transfer in addition to the mass transfer resistance of the fibers themselves. Based on the data in Table 4, a reasonable estimate for the $K \cdot A$ parameter is $0.4 \mathrm{gpm}$ if the water flow rate exceeds $0.55 \mathrm{gpm}$ and if the air flow rate exceeds $50 \mathrm{scfh}$.

Table 1. Value of VOC Transfer Parameter $(\mathrm{K} \cdot \mathrm{A})$ at Different Experimental Conditions.

\begin{tabular}{||c|c|c|c||}
\hline \multirow{2}{*}{ VOC } & \multicolumn{2}{|c|}{ Flow Rate } & \multirow{2}{*}{ K·A (gpm) } \\
\cline { 2 - 4 } & Air (scfh) & Water $(\mathrm{gpm})$ & 0.42 \\
\hline \multirow{3}{*}{ Toluene } & 50 & 0.55 & 0.40 \\
\cline { 2 - 4 } & 50 & 0.33 & 0.25 \\
\cline { 2 - 4 } & 50 & 0.22 & 0.41 \\
\cline { 2 - 4 } Methylene Chloride & 25 & 0.55 & 0.38 \\
\cline { 2 - 4 } & 50 & 0.55 & 0.28 \\
\cline { 2 - 4 } & 50 & 0.22 & 0.23 \\
\hline
\end{tabular}

\subsection{Continuous Batch Mode Operation}


As will be discussed in Section 7.2 of this report, we will use the contactor in a continuous recirculation mode in which a batch volume of solution is circulated through the contactor. VOCcontaminated water produced by the condenser will be periodically mixed in with the recirculation stream and VOC-depleted water will be periodically discharged. We performed such experiments with methylene chloride and toluene for at least three cycles each to show that this system design can remove VOCs continuously. In the first cycle, the starting concentrations for toluene and methylene chloride in the 3.5-gallon batch were 170 and 1,500 ppmw, respectively. After one hour, 0.6 gallon of treated solution was discharged and 0.6 gallon of fresh VOC/water mixture was mixed in with the batch solution. Figures 12 and 13 show the VOC removal performance of the system. After the first cycle, the concentrations in the discharged water were 30 ppmw for methylene chloride and 3 ppmw for toluene. The starting concentrations for cycle 2 and additional cycles were 250 and 30 ppmw respectively because of the 0.6 gallon to 3.5 gallon dilution factor. The end concentrations of cycle 2 and subsequent cycles were 2 to 5 ppmw for methylene chloride and less than $2 \mathrm{ppmw}$ for toluene. Based on the concentration in the VOC/water mixture treated, the system demonstrated $99.5+\%$ VOC removal.

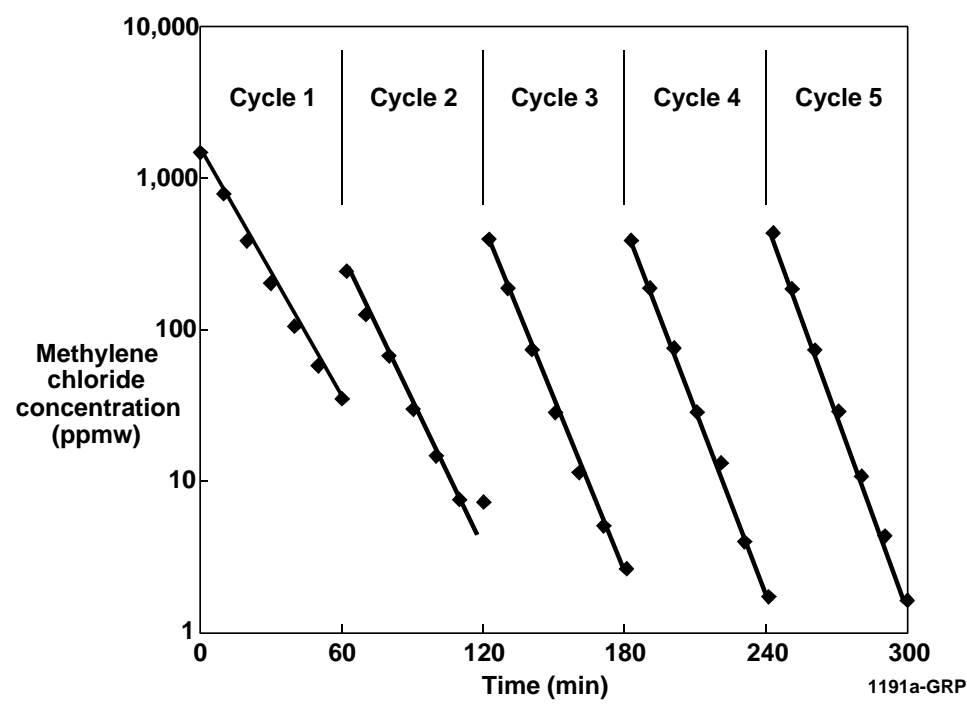

Figure 3. Removal of methylene chloride from water in a semi-continuous batch system operating in 60-minute cycle mode. A 0.6 gallon volume is exchanged every 60 minutes, so the continuous treatment capacity is $0.6 \mathrm{gph}(0.01 \mathrm{gpm})$. 


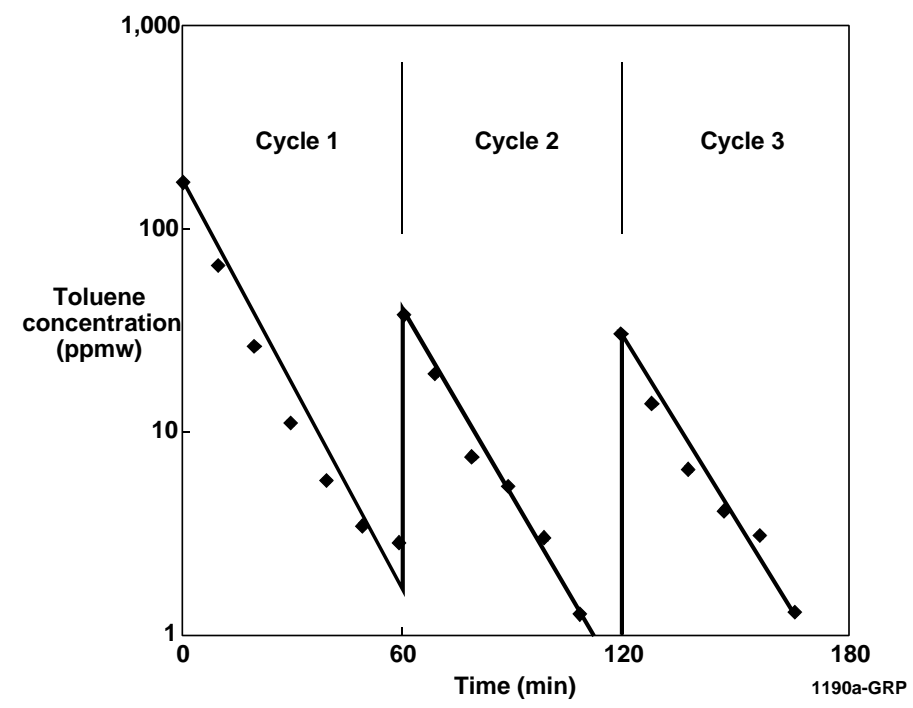

Figure 4. Removal of toluene from water in a semi-continuous batch system operating in 60minute cycle mode. A 0.6 gallon volume is exchanged every 60 minutes, so the continuous treatment capacity is $0.6 \mathrm{gph}(0.01 \mathrm{gpm})$.

\section{MEMBRANE MODULE TESTING}

A total of 29 different experiments were carried out with regular and baffled modules using TCE as the model VOC component. Baffled modules showed a substantial improvement in selectivity over the regular modules, because of improved turbulence on the feed side of the membrane. The higher turbulence is also evidenced by an increase in the feed-to-residue pressure drop of baffled modules compared to regular modules. Based on the results obtained, we used an effective VOC/nitrogen selectivity of 25 in the design calculations presented in Section 7.

\subsection{Experimental Procedures}

Regular modules and modules containing feed-side baffles were tested at MTR in a pilotscale membrane separation system. The system can hold up to three modules in series and can operate in full-recirculation mode, in which the permeate and the residue gas are returned to the inlet of the feed gas compressor. The maximum feed pressure is $130 \mathrm{psig}$, and the maximum feed flow rate is $40 \mathrm{scfm}$. A vacuum pump in the permeate line allows the permeate pressure to be as low as 1 psia. Sample ports are present in the feed, residue and permeate lines from which samples are taken for injection into a gas chromatograph. The VOC concentrations measured are entered into a computer program together with the operating conditions, such as the flow rates and pressures. The program contains a mathematical model of the spiral-wound modules using the basic transport equation (2) and calculates from the experimental results the pressure normalized fluxes of the permeants through equation (3) and the effective selectivities through equation (6). 
The modules used in the experiment were three regular modules and three modules with feed-side baffles. Each baffled module contained two baffles, which force the feed gas to make two $180^{\circ}$ turns as the gas makes it way through the module. Thus, the pathway for the gas is about three times as long and the feed gas velocity in the modules is increased by a factor of about three over that in the regular modules.

\subsection{Module Performance}

Figure 14 shows the effective TCE over nitrogen selectivity calculated from experiments with baffled and regular modules as a function of the flow rate of the feed gas. Three observations can be made from this figure:

(1) Baffled modules are much more efficient for the separation of TCE (and other VOCs) from nitrogen than regular modules.

(2) The effective selectivity increases with increasing feed gas flow rate.

(3) The increase in selectivity is less more pronounced with regular modules then with baffled modules.

All three observations are in agreement with our understanding that transport in regular modules is substantially limited by an external transport resistance on the feed side of the membrane and that improved turbulence will improve the separation characteristics of the modules.

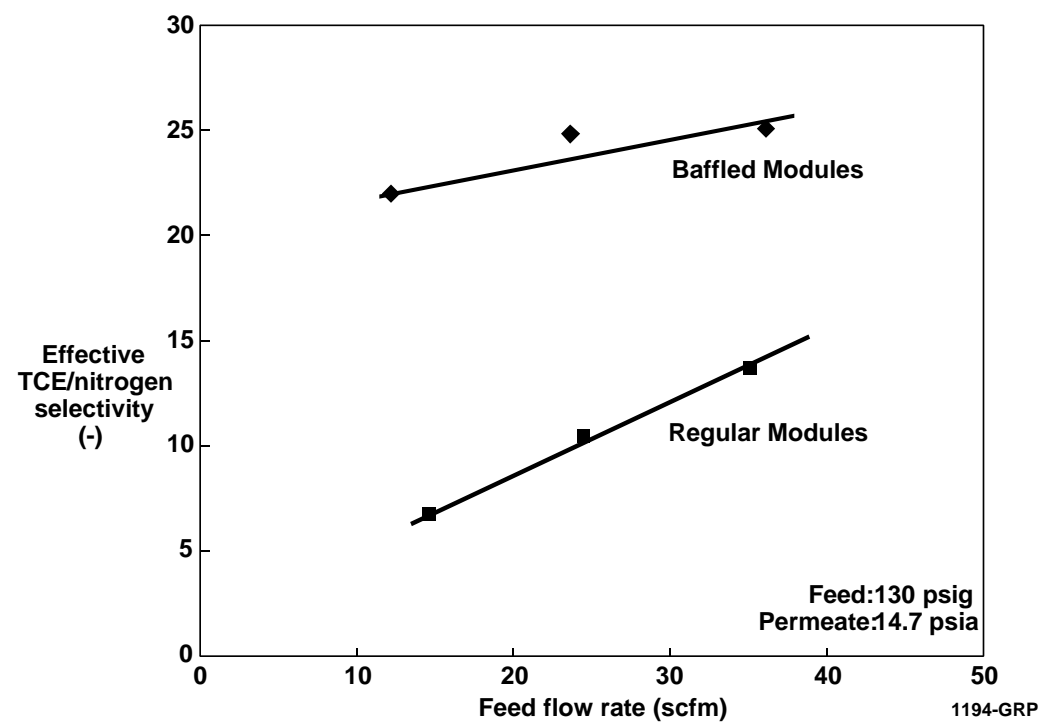

Figure 5. Effective selectivity for TCE over nitrogen of baffled and regular modules as a function of the feed gas flow rate. Feed pressure: 130 psig; permeate pressure: 14.7 psia. 
To further characterize the performance of baffled modules we varied the feed and permeate pressures. Figure 15 gives a set of representative results in a plot of the TCE removal achieved by three modules in series as a function of the stage-cut. The stage-cut is defined as the permeate gas flow rate divided by the feed gas flow rate. TCE removal increases with increasing stage-cut as expected, and the removal also increases with an increase in the feed-to-permeate pressure ratio across the membrane. This ratio is increased by increasing the feed pressure and/or by decreasing the permeate pressure-either method requires energy for compression. The optimum pressure ratio is that which allows the desired separation to be performed at the lowest cost. The main conclusion to be drawn from Figures 14 and 15 is that the baffled modules perform better than the regular modules and that high VOC removals can be obtained at reasonable stage-cuts. The system designed and described in Section 7 achieves $99.8 \%$ VOC removal at a stage-cut of $60 \%$.

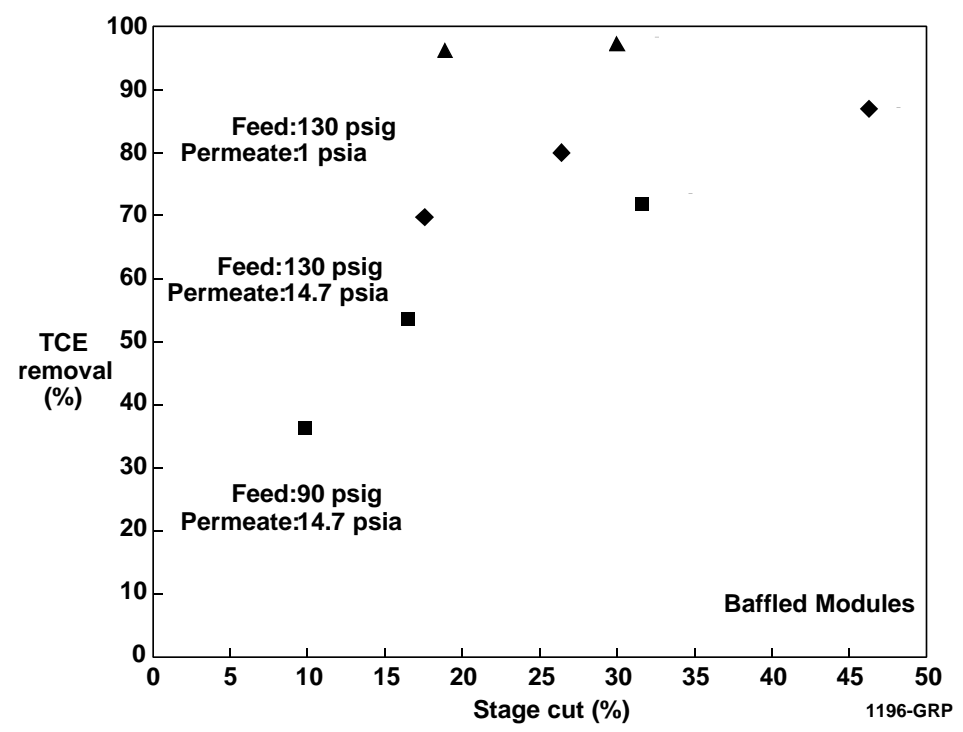

Figure 6. TCE removal achieved by three baffled modules in series as a function of the stagecut. The stage-cut is defined as the permeate flow rate divided by the feed flow rate and was varied by varying the feed flow rate.

\subsection{Feed-to-Residue Pressure Drop}

The feed-side baffles are added to the modules in an attempt to increase the feed gas velocity and thereby to increase the degree of mixing (turbulence) in the boundary layer adjacent to the membrane surface. This increase in turbulence should manifest itself in an increase in pressure drop as the feed gas makes its way through the module. Figure 16 shows the feed-toresidue pressure drop of a baffled module as a function of the feed gas flow rate and at two different feed pressures. As expected, the pressure drop increases with the flow rate and decreases with the feed pressure, that is, the pressure drop increases with increasing kinetic energy of the feed gas. Comparison with the data for a regular module shows that the pressure drop in the baffled module is indeed much higher than the pressure drop in a regular module. 
We expect to use large-scale 8-inch modules for the first stage of the system described in Section 7. The first stage will operate at 190 psia feed pressure and will be fed with almost 250 $\mathrm{scfm}$ of air (100 scfm feed plus $150 \mathrm{scfm}$ recycle). A friction factor analysis on the baffled module data given in Figure 16 predicts that the pressure drop is 6 psid for the first module and only 1 psid for the last module. Thus, it seems feasible to use several baffled modules in series while keeping the combined feed-to-residue pressure drop within 10 to 20 psid.

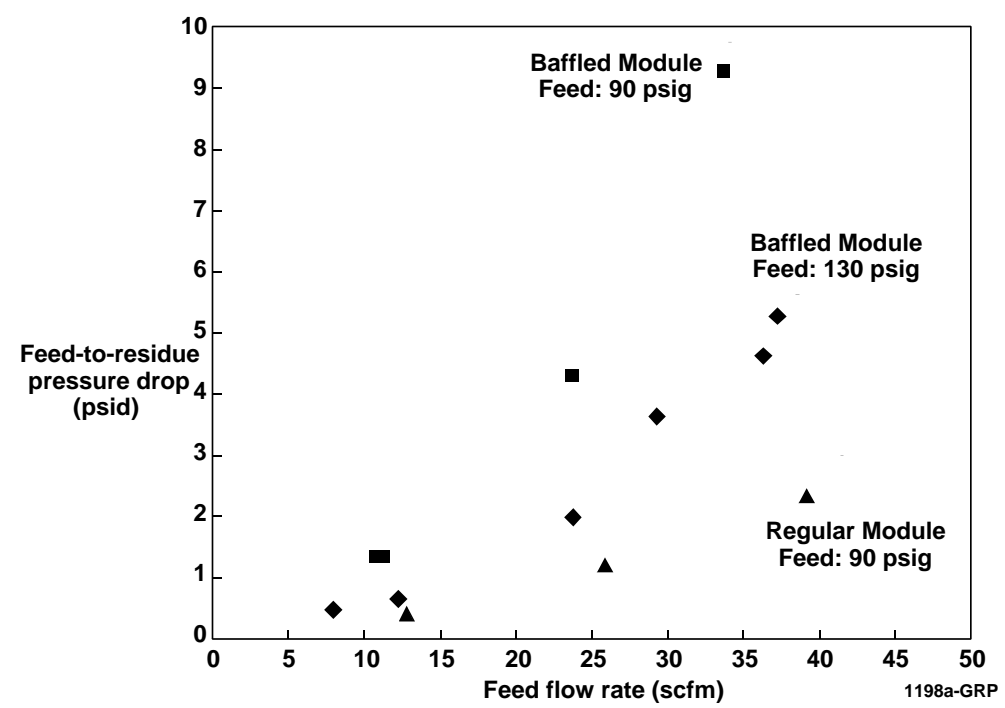

Figure 7. Feed-to-residue pressure drop observed for a baffled module and a regular module as a function of the feed gas flow rate.

\section{SYSTEM DESIGN}

Using the module results discussed in Section 6 and the stripping results described in Section 5, we performed a design study to determine the optimum configuration for a VOC removal/recovery system. The base-case parameters used in these design calculations are given in Table 5. The design calculations were performed using a commercially available process simulator, ChemCad (ChemStations, Houston. TX) to which MTR has added its own proprietary membrane separation unit operation. The membrane system configuration and operating conditions are discussed in Section 7.1, and the details of the water separation system are discussed in Section 7.2.

The base-case system uses a total of $85 \mathrm{~m}^{2}$ membrane area and $110 \mathrm{hp}$ for compression to achieve $99.8 \%$ VOC removal from a 100 -scfm air stream. The membrane area is divided over two membrane stages, with the first stage divided into two separate steps. We envision the first step to be one commercial-scale 8-inch-diameter module, the second step to comprise four 8inch-modules in series, and the second stage to comprise two 6-inch-diameter modules in series. Of the $110 \mathrm{hp}$ requirement, $80 \mathrm{hp}$ will be used by the screw compressor in the first stage and 30 hp will be used by the liquid-ring pump in the second stage. 
Table 2. Design Parameters.

\begin{tabular}{||l|l||}
\hline \multicolumn{1}{|c||}{ Parameter } & \multicolumn{1}{c||}{ Value } \\
\hline Air flow rate & $100 \mathrm{scfm}$ \\
\hline Water vapor concentration in air inlet & $1.5 \%$ by volume \\
\hline VOC concentration in air inlet & $5,000 \mathrm{ppmv}$ \\
\hline VOC concentration in air vent & $\begin{array}{l}10 \mathrm{ppmv}(99.8 \% \text { VOC } \\
\text { removal) }\end{array}$ \\
\hline Effective VOC/nitrogen selectivity & 25 \\
\hline Effective VOC/oxygen selectivity & 12 \\
\hline Coolant temperature & $1{ }^{\circ} \mathrm{C}$ \\
\hline VOC vapor pressure at $5^{\circ} \mathrm{C}$ & $3.6 \mathrm{psia}$ (methylene chloride) \\
\hline \hline
\end{tabular}

\subsection{Selection of Configuration and Operating Conditions}

The system configuration originally proposed is given in Figure 17. The air containing the VOC is compressed in a screw compressor and passes through an air-cooled condenser, where mostly water and some VOC condense. The condensate is treated by a water separation system, which is described in detail in Section 7.2. The bleed air from the condenser enters the first membrane stage, where the air is split into a VOC-depleted stream (the vent air) and a VOCenriched permeate stream. The permeate is recompressed by a liquid-ring pump and passes through a second air-cooled condenser, followed by a condenser at $5^{\circ} \mathrm{C}$ (cooled by coolant from a small chiller). The bleed from the condenser enters the second membrane stage to separate the stream into a VOC-enriched stream, which is recirculated to the front of the liquid-ring pump, and a VOC-depleted stream, which is recirculated to the front of the screw compressor. The recirculation of VOC-enriched air in the second membrane stage creates a VOC concentration loop which ensures that VOC will condense in the condenser. Thus, the system produces three different streams from the feed:

(2) Clean water: VOC concentration 1 ppmw or less.

(3) Liquid VOC for disposal.

The goals for the VOC concentration in the air and water streams to be discharged reflect general targets and are not based on specific regulations. The exact discharge limits will vary from site to site depending on the particular VOCs present and local regulations. 


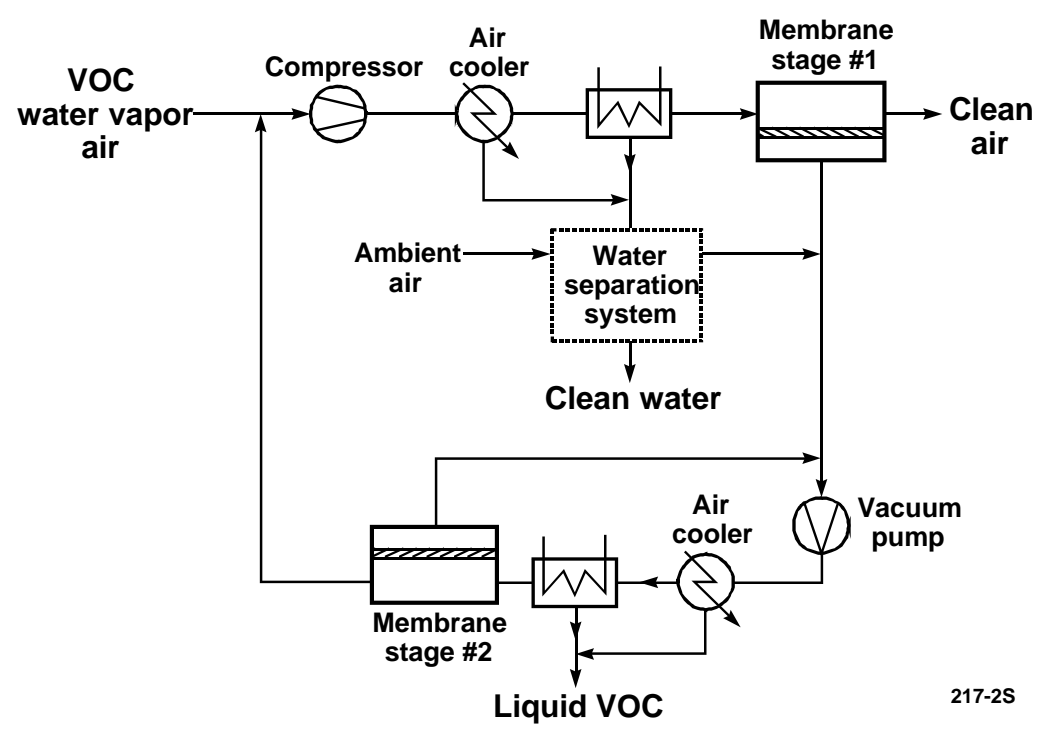

Figure 8. Schematic of membrane system for the removal of VOCs from remediation off-gases. The system produces clean air (VOC concentration 10 ppmv or less), clean water (VOC concentration 1 ppmw or less), and liquid VOC for disposal.

\section{Two-step Versus One-step Configuration in First Membrane Stage.}

The configuration shown in Figure 17 uses the first membrane stage to achieve two objectives: (1) to produce a stream concentrated in VOC to be fed to the VOC condensation section (see also Figure 5), and (2) to produce a stream depleted in VOC to be vented. These two objectives cannot be optimized simultaneously in one membrane stage, so we performed design calculations in which the first membrane stage is divided into two separate steps. As is shown in Figure 18, the first step produces the VOC-concentrated stream as the permeate stream, and its residue stream is fed to the second step. This produces the VOC-depleted stream as the residue stream, and its permeate stream is recirculated to the front of the screw compressor. The two-step configuration allows for independent optimization of objectives (1) and (2), which substantially improves the efficiency of the system. Figure 19 compares the membrane area and horse power requirements of a one-step configuration versus a two-step configuration at different VOC removal levels. The calculations were performed using the base-case parameter values given in Table 5. The two-step configuration reduces the horse power and membrane area requirements by a factor of almost three. Therefore, the two-step configuration shown in Figure 18 was selected as the configuration to be used. 


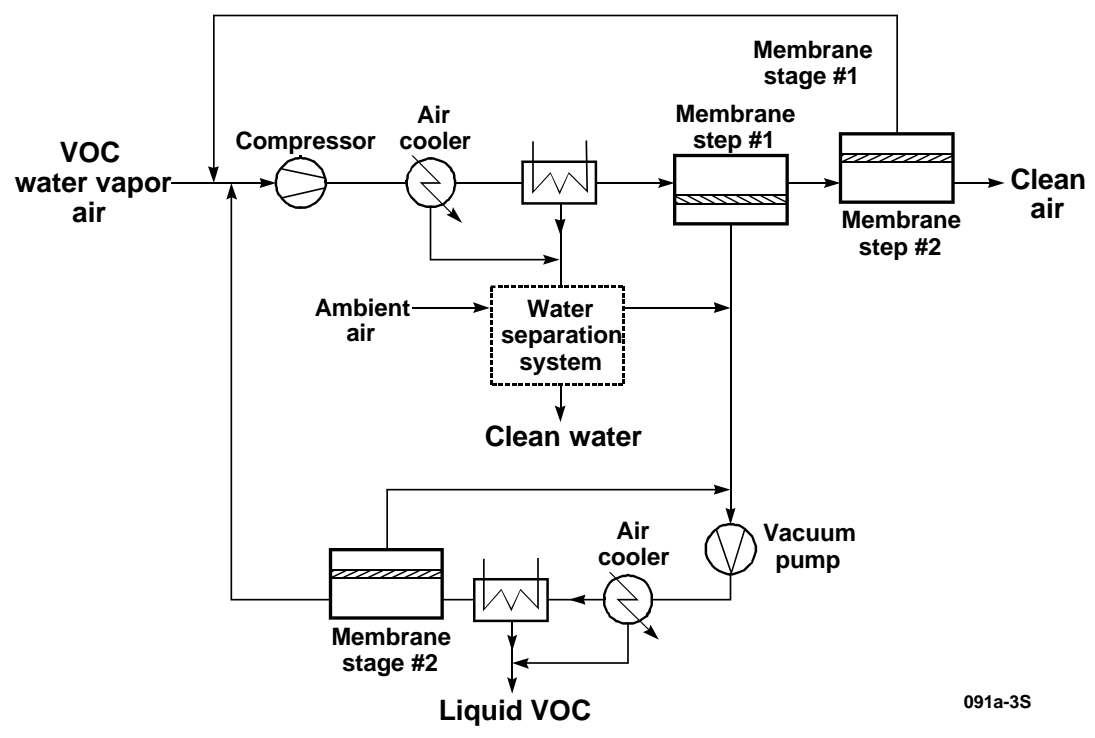

Figure 9. Schematic of membrane system for the removal of VOCs from remediation off-gases using a two-step configuration in the first membrane stage. The system produces clean air (VOC concentration $10 \mathrm{ppmv}$ or less), clean water (VOC concentration $1 \mathrm{ppmw}$ or less) and liquid VOC for disposal.

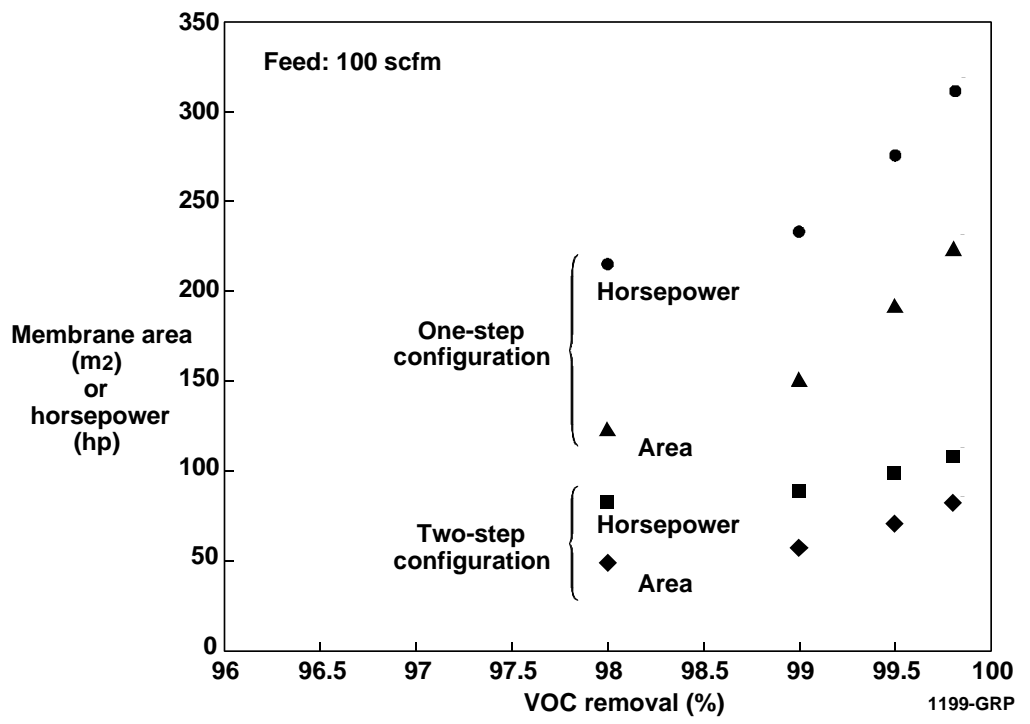

Figure 10. Membrane area and horsepower requirements calculated for the one-step (Figure 17) and two-step (Figure 18) configurations for different VOC removals. The twostep configuration is clearly more efficient and is the preferred choice. 


\section{Optimization of Two-Step Configuration}

The two-step configuration is more efficient because the VOC concentration between the two steps can be chosen independently, providing the design engineer with one additional operating parameter that can be optimized. We will refer to this concentration the "Intermediate VOC Concentration"; Figure 20 gives the membrane area and horsepower requirements as a function of this concentration as calculated for the base-case system. A broad minimum occurs in both area and horsepower in the range 1,500 to 3,000 ppmv VOC. The minimum corresponds to a value of approximately 5,000 ppmv for the VOC concentration in the permeate of the second step, which is recirculated to the feed stream. Since the feed stream contains 5,000 ppmv VOC, the optimum system avoids mixing streams of different VOC concentrations, which is favorable from an energy standpoint. We can, therefore, simplify the optimization process by using the "controller option" available in the process simulator, which is able to control the Intermediate VOC Concentration to ensure that the VOC concentration in the permeate from the second step is equal to the VOC concentration in the system feed stream.

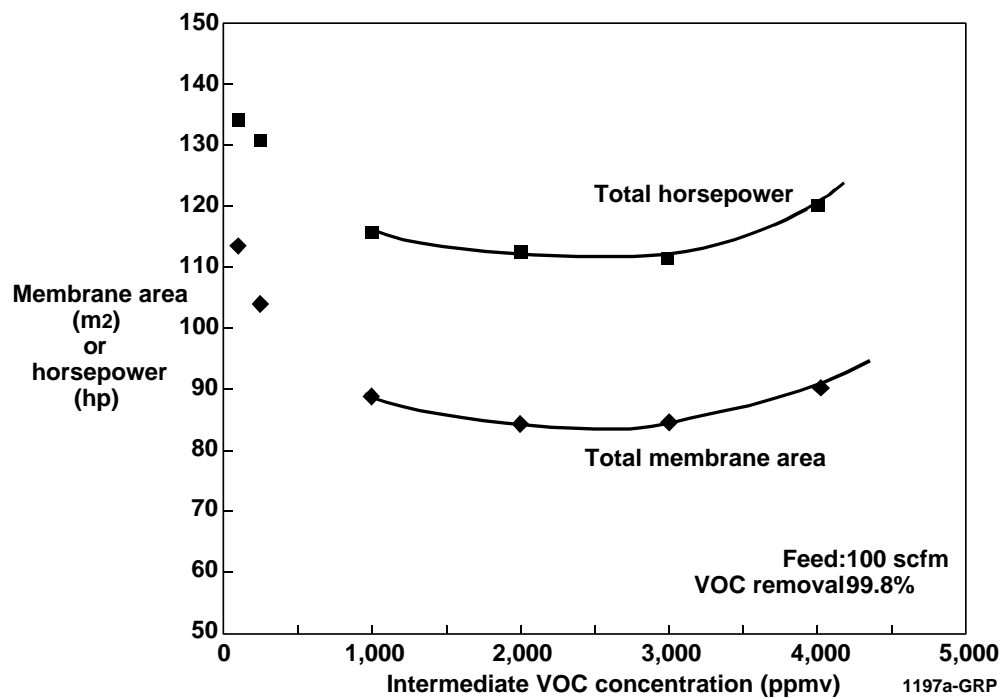

Figure 11. Membrane area and horsepower requirements calculated for the two-step configuration as a function of the Intermediate VOC Concentration between the two steps. The minimum corresponds to the VOC concentration in the permeate of the second step being approximately equal to the VOC concentration in the system feed stream.

\section{Selection of Feed Pressure in First Stage}

Design calculations performed with a first-stage pressure between 100 and 190 psia showed that the system requires less area and less horsepower as the pressure is increased. Since 190 psia is the maximum pressure available from a single-stage air compressor, this pressure was selected as the base-case pressure for the high-pressure side of the first stage.

Selection of the Permeate Pressure in the First Step of the First Stage 
As shown in Figure 18, the permeate from the first step is compressed by a liquid-ring pump; the permeate pressure will be determined by the capacity of the pump. Because the compression ratio achieved by a liquid-ring pump is typically about eight, the choice of the permeate pressure also determines the pressure at which the second stage operates. Figure 21 gives the calculated membrane area and horsepower requirements as a function of the permeate pressure of the first step. In these calculations, the feed pressure of the second stage is fixed at eight times the permeate pressure. Figure 21 shows the horsepower required increases slightly as the permeate pressure increases. This is because the higher permeate pressure reduces the efficiency of the first step, which results in an increase in the permeate flow rate. The membrane area required in the second stage decreases with increasing permeate pressure because the higher permeate pressure translates to a higher feed pressure in the second stage. The net effect of the two trends is an optimum permeate pressure in the range of 7.5 to 12.5 psia; we have selected 10 psia as the base-case permeate pressure. This means that the base-case feed pressure of the second stage is 80 psia (65 psig).

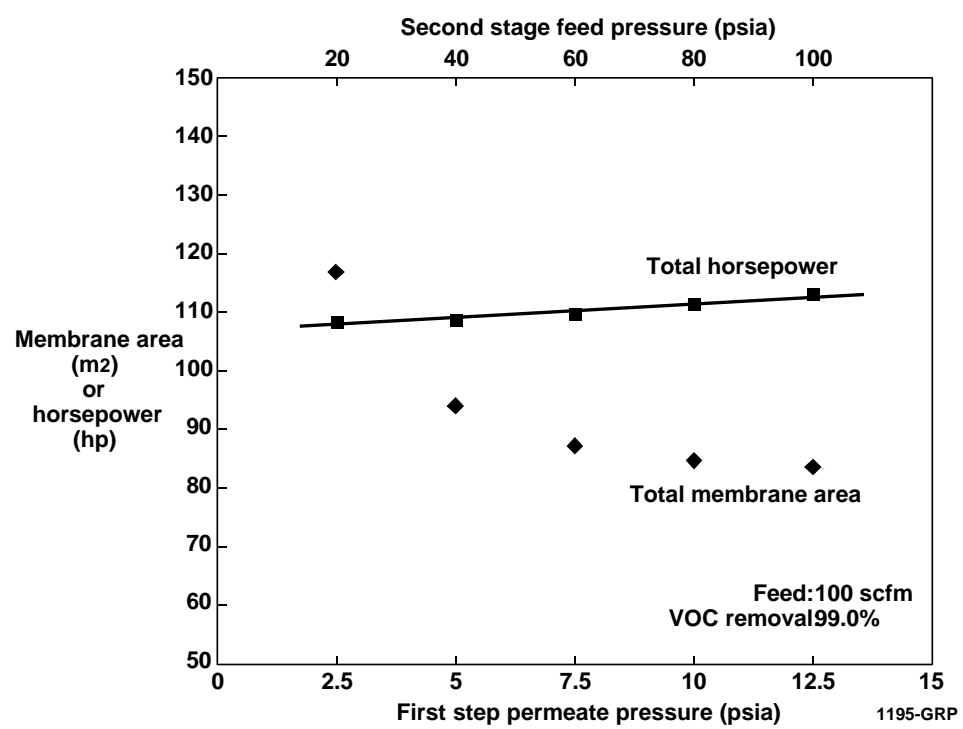

Figure 12. Membrane area and horsepower requirements calculated for the two-step configuration as a function of the permeate pressure of the first step (see Figure 18). The compression ratio achieved by the liquid-ring pump is fixed at eight, which means that the feed pressure in the second stage is directly coupled to the permeate pressure.

\subsection{Water Separation System Design}

The overall system design shown in Figure 18 includes a water separation system to clean up the aqueous condensate produced by the condensers in the first membrane stage. The detailed flow diagram of the water separation system is shown in Figure 22. A 100-scfm air stream containing $2.5 \%$ water vapor carries about $0.9 \mathrm{gal} / \mathrm{hr}$ of water, so the amount of condensate will be produced at a rate of $1 \mathrm{gal} / \mathrm{hr}$ or less. As shown in Figure 22, the condensate is collected in a vessel from which it is periodically discharged. To handle this intermittent flow, we have designed the continuous recirculation system shown in Figure 22. A batch volume of 3 gallons 
is continuously recirculated from buffer volume \#2 through two membrane contactors in series and is returned to the buffer volume. Periodically, 1 gallon is discharged from the batch volume, after which 1 gallon of condensate contaminated with VOCs is added to the batch volume. The system will operate in the following sequence controlled by the programmable logic controller (PLC) of the membrane system:

a. Condensate collects in buffer volume \#1, which is at the pressure of the condenser. The increasing liquid level in buffer volume \#1 trips level switch \#1 which turns three-way valve \#1 to discharge water from the batch volume.

2. The discharge causes the level in buffer volume \#2 to drop. This trips level switch \#2, which turns three-way valve \#1 back to the normal position. Subsequently, three-way valve \#2 is turned to allow condensate to be added to the batch volume, and valve \#3 is opened to release the condensate.

3. The amount of condensate added is controlled by a timer. The timer closes valve \#3 and turns three-way valve \#2 back to the normal position. The system will remove VOCs from the batch volume until the subsequent discharge is triggered by the level switch \#1 in buffer volume \#1.

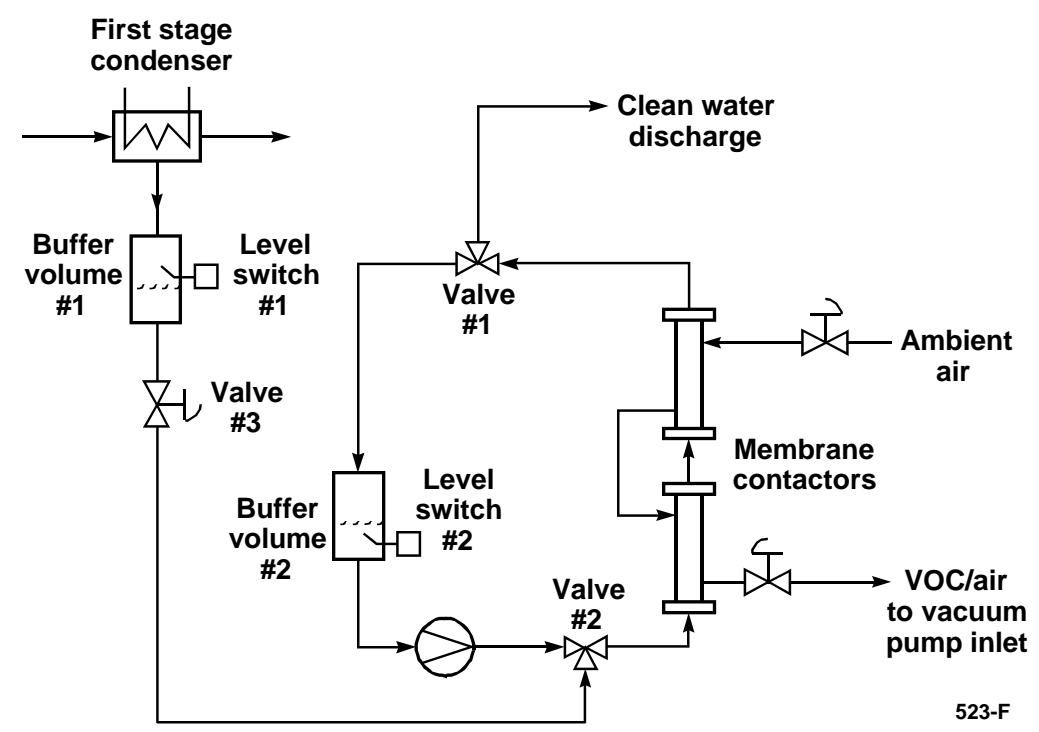

Figure 13. Schematic of the water separation system which removes VOCs from the condensate produced by the condenser in the first stage.

We predicted the performance of the water separation system using the parameter values listed in Table 6. The results of the simulation are shown in Figure 23. The first three cycles are under base-case conditions. The starting VOC concentration in each cycle is $330 \mathrm{ppmw}$, which is the result of the three-to-one dilution achieved by introducing 1 gallon of condensate containing 1,000 ppmw VOC into the 3-gallon batch volume. After 60 minutes, the VOC 
concentration has been reduced to $0.0053 \mathrm{ppmw}$ (5.3 ppbw). Then, 1 gallon is discharged and the next 1-gallon batch of condensate is added. For the fourth cycle it is assumed that the condensate contains 5,000 ppmw VOC, a concentration so high that it is unlikely to occur. After the initial dilution, the starting concentration is $1,650 \mathrm{ppmw}$, which is reduced in 60 minutes to $0.026 \mathrm{ppmw}$ (26 ppbw). Cycle \#5 is again at base-case conditions. During cycle \#6, it was assumed that the condensate is produced at a rate of $1.5 \mathrm{gph}$, or $50 \%$ faster than the base-case rate of $1 \mathrm{gph}$. (1.5 gph means that the 100-scfm air stream contains $4.2 \%$ water vapor, which is highly unlikely). The higher condensate production rate means that cycle \#6 is cut short to 40 minutes, and that after 40 minutes the VOC concentration has been reduced to $0.21 \mathrm{ppmw}(210 \mathrm{ppbw})$. Cycle \#7 is once again a base-case example. Figure 23 shows that the water separation system will produce very clean water for discharge. Under normal conditions, the VOC concentration in the discharge is less than $0.01 \mathrm{ppmw}$ (10 ppbw), and, even under the most challenging conditions, the VOC concentration is predicted to be less than $0.5 \mathrm{ppmw}$ (500 ppbw).

Table 6. Parameter Values Used to Predict Water Separation System Performance

\begin{tabular}{||l|l|l||}
\hline \multicolumn{1}{|c|}{ Parameter } & \multicolumn{1}{|c||}{ Base Case } & \multicolumn{1}{c||}{ Variation } \\
\hline Batch volume & 3 gallon & \\
\hline $\begin{array}{l}\text { Water recirculation flow } \\
\text { rate }\end{array}$ & $1 \mathrm{gpm}$ & \\
\hline Air flow rate & $1 \mathrm{scfm}$ & \\
\hline Mass transfer parameter & $\begin{array}{l}0.8 \mathrm{gpm} \\
\text { (Two contactors in series })\end{array}$ & \\
\hline Transfer volume & 1 gallon & $\begin{array}{l}40 \text { minutes } \\
(1.5 \text { gph condensate prod. })\end{array}$ \\
\hline Cycle time & $\begin{array}{l}60 \text { minutes } \\
(1 \mathrm{gph} \text { condensate production })\end{array}$ & $5,000 \mathrm{ppmw}$ \\
\hline Condensate VOC conc. & $1,000 \mathrm{ppmw}$ &
\end{tabular}




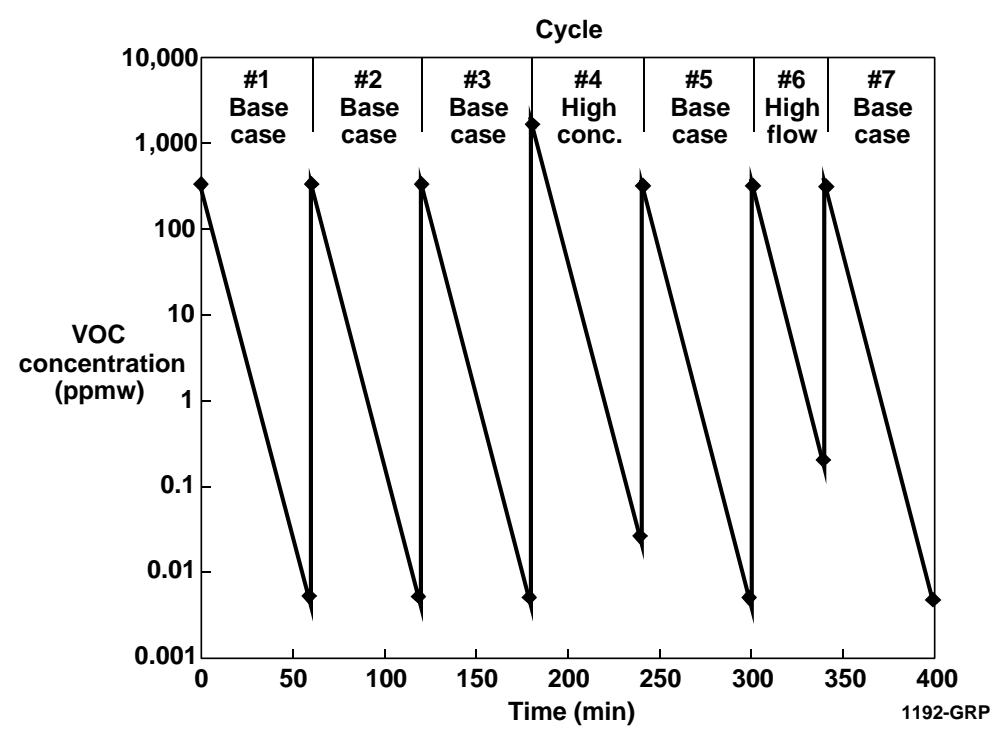

Figure 14. Performance of the water separation system as predicted under varying conditions. Under base-case conditions, the water discharged will contain less than 0.01 ppmw (10 ppbw) VOC. An unusually high VOC starting concentration and/or high water condensation rate can lead to higher VOC concentration in the discharged water, but a VOC concentration over 1 ppmw can be ruled out with a high degree of confidence.

\section{TECHNICAL AND ECONOMIC ANALYSIS}

\subsection{System Performance}

The system design presented in the previous section is based on a VOC concentration of $5,000 \mathrm{ppmv}$ in the feed and $10 \mathrm{ppmv}$ in the vent. Methylene chloride was used to represent the VOC volatility (required to calculate condenser performance). In this section we will address how the base-case system, that is, the system with a fixed membrane area and fixed compressor and pump capacities, will react to variations in the characteristics of the stream to be treated and the operating conditions.

\section{Variation of VOC}

The VOC over nitrogen selectivity of the membrane does not vary significantly with the nature of the VOC, unless the VOC is extremely volatile. An example would be propane, but VOCs of such high volatility are not expected in remediation applications. The volatility of the VOC will, however, determine the performance of the condenser, particularly in the second membrane stage. Table 7 shows the vent concentration expected with a feed containing respectively 5,000 ppmv toluene, 5,000 ppmv TCE and 5,000 ppmv methylene chloride. From Table 7 it can be seen that the vent concentration increases with increasing vapor pressure of the VOC, although the increase is 
quite small. This is because the recirculation loop around the condenser compensates for a decrease in condenser performance by recirculation of a more concentrated stream. Table 7 also shows that the presence of mixed VOCs will not lead to increased vent concentrations. The only exception to this rule would be the presence of VOCs that are not miscible in the liquid phase, which is highly unlikely. Since methylene chloride (the base-case VOC) is one of the more volatile organics to be encountered, we conclude that the vent VOC concentration will typically be 10 ppmv or less.

Table 7. Effect of VOC Volatility and VOC Mixture Composition on Vent Concentration.

\begin{tabular}{||l|c|c|c||}
\hline \multicolumn{1}{|c|}{ VOC } & $\begin{array}{c}\text { VOC in Feed Stream } \\
(\mathrm{ppmv})\end{array}$ & $\begin{array}{c}\text { VOC in Vent Stream } \\
(\mathrm{ppmv})\end{array}$ & $\begin{array}{c}\text { Pure VOC vapor } \\
\text { pressure at } 5^{\circ} \mathrm{C} \\
(\mathrm{psia})\end{array}$ \\
\hline Methylene chloride & 5,000 & 10 & 3.6 \\
\hline TCE & 5,000 & 8.3 & 0.45 \\
\hline Toluene & 5,000 & 8.1 & 0.18 \\
\hline $\begin{array}{l}\text { Methylene chloride } \\
\text { Toluene }\end{array}$ & 2,500 & 4.7 & \\
\hline
\end{tabular}

\section{VOC Feed Concentration Variation}

Figure 24 shows a plot of the VOC concentration in the vent as a function of the VOC concentration in the feed stream over the range of 100 ppmv to $10,000 \mathrm{ppmv}$ ( $1 \%$ by volume). The vent concentration increases with the feed concentration, but the increase is substantially less than linear. The reason is that, as the VOC concentration in the feed increases, the efficiency of the VOC condensation section is greatly increased. 


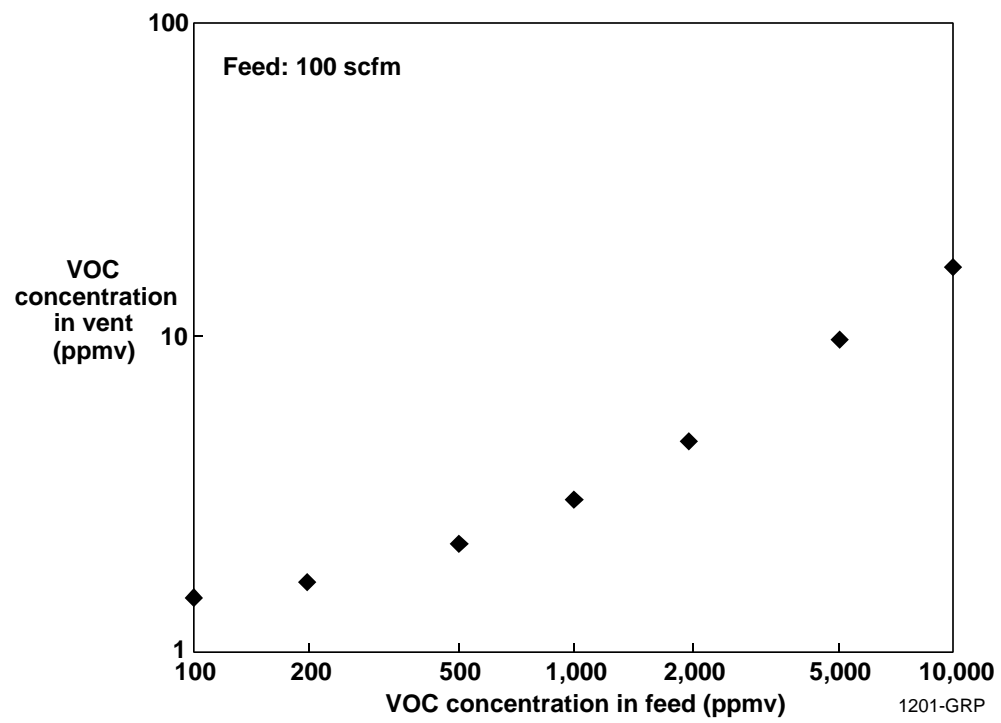

Figure 1. VOC vent concentration in vent as a function of the VOC feed concentration. Feed flow rate: $100 \mathrm{scfm}$; total membrane area: $85 \mathrm{~m}^{2}$; total horsepower: $110 \mathrm{hp}$.

A change in VOC concentration will also change the ratio of VOC to water in the condensate produced by the condenser in the second stage. Table 8 gives the calculated weight percentage of VOC in that condensate as a function of the VOC concentration in the inlet air. The water vapor concentration in the inlet air is maintained constant at $1.5 \%$ by volume. Table 8 shows clearly that the condensate is much more concentrated in VOC relative to water than the inlet air. This is important because the combined volume of water and VOC determines the disposal costs.

Table 8. Composition of Condensate Produced by the Condenser in the Second Stage for Different VOC Inlet Concentrations. The water vapor concentration in the inlet air is $1.5 \%$. The balance of the VOC concentration in the condensate is water.

\begin{tabular}{|c|c|}
\hline $\begin{array}{c}\text { VOC Concentration in inlet } \\
\text { air } \\
(\mathrm{ppmv})\end{array}$ & $\begin{array}{c}\text { VOC Concentration in } \\
\text { Condensate }(\% \text { by weight })\end{array}$ \\
\hline 5,000 & 80 \\
2,000 & 62 \\
1,000 & 45 \\
500 & 30 \\
200 & 16 \\
100 & 10 \\
\hline
\end{tabular}




\section{Feed Flow Rate and VOC Vent Concentration Variations}

Figure 25 gives the membrane area and horsepower requirements of the membrane system as a function of the VOC vent concentration. The feed stream contains 5,000 ppmv VOC and has a $100 \mathrm{scfm}$ flow rate. As expected, the membrane area and horsepower required decrease with an increasing vent concentration. The reduction in membrane area is mostly in the second step of the first stage, which reduces the volume of gas recirculated to the front of the screw compressor. Consequently, the reduction in horsepower is mostly in the first-stage compressor.

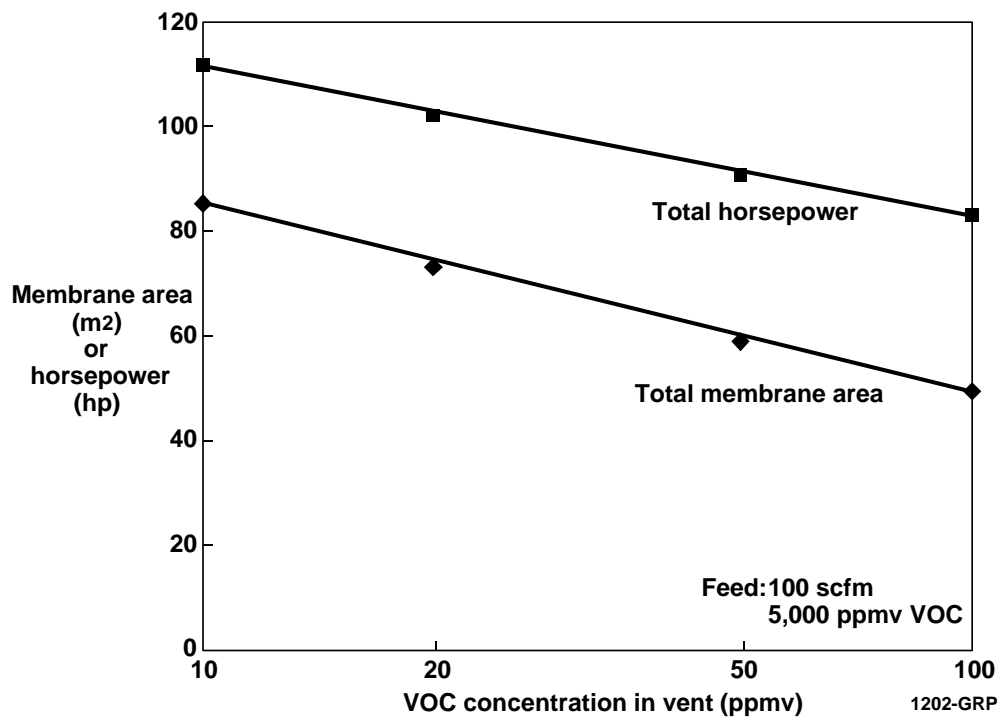

Figure 2. Membrane area and horsepower requirements calculated for the two-step configuration as a function of the VOC vent concentration.

If the base-case system produces a lower VOC vent concentration than desired, the system can be easily modified to treat gas at a higher flow rate than the design value. This is achieved by removing one or more modules from the second step; Figure 26 shows the result of this action. At the base-case operating point, four modules are used in the second step and a 10-ppmv vent concentration is achieved at a capacity of $100 \mathrm{scfm}$. The next three points in the graph represent operation with respectively three, two and one modules in the second step. With one module, the capacity has doubled to $200 \mathrm{scfm}$, but the vent concentration has increased to $1,470 \mathrm{ppmv}$. An operating point of more practical value uses three modules in the second step and achieves a vent concentration of $93 \mathrm{ppmv}$ ( $98.1 \%$ VOC removal) at a capacity of $135 \mathrm{scfm}$, a $35 \%$ increase over the base-case value of $100 \mathrm{scfm}$. 


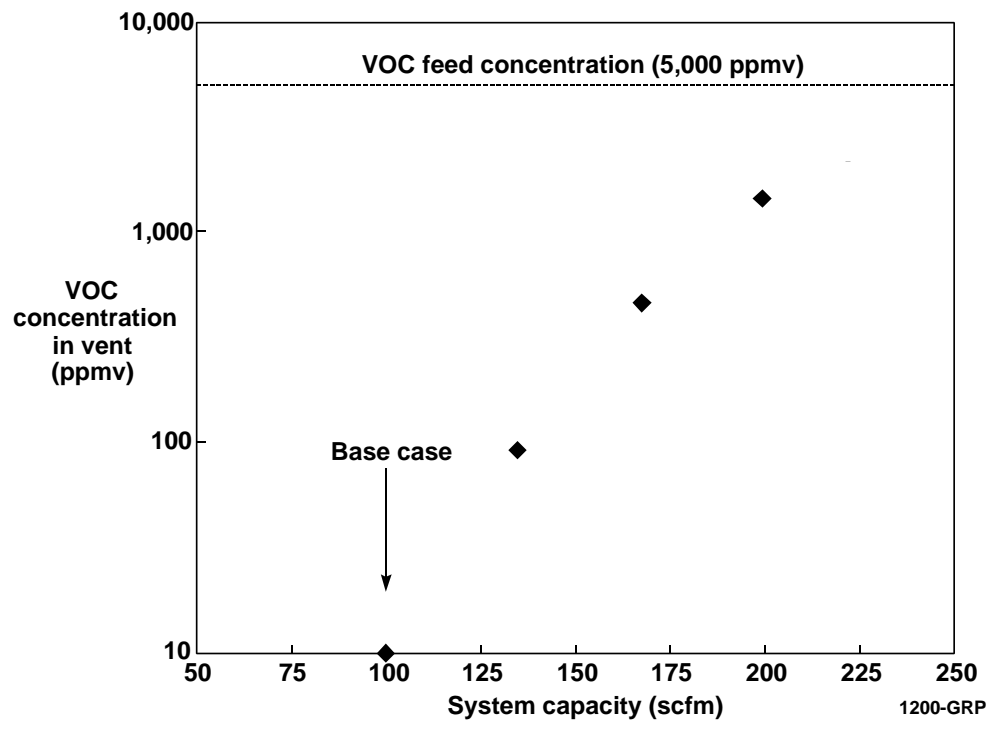

Figure 3. System capacity as a function of the VOC vent concentration. The capacity is increased by removing one or more modules from the second step, which reduces the recirculation flow rate to the compressor and increases the VOC vent concentration.

\subsection{Membrane System Cost Estimate and Comparison with Competin g Technologies}

Carbon adsorption is the vapor treatment technology most widely used with remediation off-gases, and systems are available from numerous vendors. Carbon is only economical for relatively low VOC mass removal rates; if the removal rates are high, the cost of replacing or regenerating the carbon becomes prohibitive.

Two types of carbon process are used, depending on the mass removal rate. If the VOC concentration is low, simple carbon canisters are used. These canisters are replaced when fully loaded, and the used canisters are shipped offsite for regeneration at a cost of approximately $\$ 5 / \mathrm{kg}$ of carbon. In the $0-200 \mathrm{ppm}$ VOC range, carbon will typically adsorb $5 \%$ of its weight of VOC, thus offsite regeneration costs approximately $\$ 100 / \mathrm{kg}$ of VOC adsorbed.

If the VOC concentration is in the $200-1,000$ ppm range, offsite regeneration becomes too expensive, and onsite regeneration is used. Fully automatic dual-bed regeneration systems are available for sale or as rental units. The monthly rental fee for a system treating a 100-scfm air stream with a VOC concentration below 1,000 ppmv will be approximately $\$ 7,500$. Regeneration with steam is the common practice, but the VOC removed is then contaminated with 20-30 volumes of condensed steam, so the volume of secondary waste produced is large. This presents a problem in remediation applications because the VOC/water mixture has to shipped as hazardous waste at a cost of $\$ 1.25 / \mathrm{kg} .{ }^{13}$ For this reason, a system design that regenerates the carbon with hot air and vacuum received significant attention in 1994 and $1995^{14}$. The advantage of regeneration without steam is that significantly less water is recovered, which reduces the disposal costs. However, the system experienced serious corrosion problems and the 
manufacturer is no longer in business. Therefore, for most applications the competition for the membrane system is a carbon system with on-site steam regeneration. Only at very low VOC concentrations will carbon canisters with offsite regeneration be feasible.

Table 9 lists the capital cost for the base-case membrane system, which treats $100 \mathrm{scfm}$ of air and reduces the VOC content from 5,000 to 10 ppmv. Total capital cost for a skid-mounted, turn-key system is estimated at $\$ 250,000$.

Table 9. Capital Cost Breakdown for Membrane System Treating $100 \mathrm{scfm}$ of Air Contaminated with 5,000 ppmv VOC. The vent air produced contains 10 ppmv VOC.

\begin{tabular}{||lr||}
\hline Membrane modules & $\$ 16,500$ \\
Module pressure vessels & 11,000 \\
Screw compressor & 15,000 \\
Liquid ring pump & 28,000 \\
Condenser/chiller & 10,000 \\
Water separation system & 5,000 \\
Programmable logic controller & 5,000 \\
Skid, piping, valving & 20,000 \\
System engineering, fabrication and manufacturer's margin & 135,500 \\
& \\
& \\
\end{tabular}

The operating costs are calculated for two different options: ownership and rental. The ownership option should be considered if a long-term use of the system is anticipated, whereas the rental option is suited for short-term use. Table 10 lists the operating costs for both options for the base-case system. The rental option is about $50 \%$ more expensive, but does not require an upfront investment in the system. The membrane replacement costs are based on a three-year life of the membrane modules. This life span has been demonstrated by MTR in commercial systems in the chemical industry. 
Table 10. Operating Cost Breakdown for Membrane System Treating 100 scfm of Air Contaminated with 5,000 ppmv VOC. The vent air produced contains 10 ppmv VOC. Two options are considered: ownership and rental.

\begin{tabular}{||lr|lr||}
\hline \multicolumn{2}{|c|}{ Ownership Option } & \multicolumn{2}{|c|}{ Rental Option } \\
\hline Capital depreciation $(15 \% / \mathrm{yr})$ & $\$ 37,500$ & Rental fee $(5 \% / \mathrm{month})$ & $\$ 12,500$ \\
Module replacement & 5,500 & Energy $(\$ 0.07 / \mathrm{kWh})$ & 4,200 \\
Maintenance and Labor & 25,000 & Waste Disposal $(\$ 1.25 / \mathrm{kg})$ & 3,600 \\
Energy $(\$ 0.07 / \mathrm{kWh})$ & 50,500 & & \\
Waste disposal $(\$ 1.25 / \mathrm{kg})$ & 43,000 & & \\
TOTAL per year & 161,500 & & TOTAL per month \\
& & & $\mathbf{2 0 , 9 0 0}$ \\
\hline
\end{tabular}

Repeating the calculations given in Table 10, we estimated the operating costs of the membrane system for different VOC feed concentrations. In each case, the VOC concentration in the vent stream was maintained at $10 \mathrm{ppmv}$. The resulting cost data are given in Table 11, which shows that the operating costs decrease with the VOC concentration, albeit only slightly.

Table 11. Operating Costs for the Ownership and Rental Options as a Function of the VOC Concentration in the 100 -scfm Air Stream. VOC concentration in the vent is $10 \mathrm{ppmv}$ in all cases.

\begin{tabular}{||c|c|c||}
\hline VOC Concentration in & \multicolumn{2}{|c|}{ Operating Costs (\$/month) } \\
\cline { 2 - 3 }$\left(\begin{array}{c}\text { Feed } \\
(\mathrm{ppmv})\end{array}\right.$ & Ownership Option & Rental Option \\
\cline { 2 - 3 } 10,000 & 14,500 & 21,700 \\
5,000 & 13,500 & 20,900 \\
1,000 & 9,800 & 15,600 \\
100 & 8,400 & 12,800 \\
\hline
\end{tabular}

Figure 27 compares the membrane system operating costs with the costs of carbon canisters and with carbon with steam regeneration. The carbon canister costs are based on 5\% carbon loading and a $\$ 5 / \mathrm{kg}$ off-site regeneration costs, that is, $\$ 100 / \mathrm{kg}$ of VOC removed. The cost of the steam-regenerated carbon system is based on a monthly rental fee of $\$ 7,500$ and a liquid disposal cost of $\$ 1.25 / \mathrm{kg}$. Taking into account that 25 times more water than VOC is recovered, the disposal costs amount to $\$ 31 / \mathrm{kg}$ of VOC removed. Figure 27 shows that carbon systems are preferred at VOC concentrations under 100 ppmv. At higher VOC concentration, the strong dependence of the operating costs on the amount of VOC removed (the relationship is almost linear) makes the carbon systems expensive. The membrane system then becomes the preferred approach. The operating costs of the membrane system do not depend highly on the amount of VOC removal and are dominated by capital and energy costs, which are approximately 
proportional to the volume of air treated. Figure 27 shows that the cost of carbon canisters to remove the final $10 \mathrm{ppmv}$ of VOC from the air stream is low-about $\$ 1,000$ per month. Thus, the total monthly operating costs for a 100 -scfm air stream containing $1 \%(10,000$ ppmv) VOC is about $\$ 15,500$ (ownership option). It is interesting to consider a process in which the membrane system reduces the VOC concentration to $100 \mathrm{ppmv}$ and carbon canisters are used to treat the discharge stream. The monthly costs for the canisters will be about $\$ 10,000$ (see Figure 27 ), whereas the monthly costs of the membrane system drop from $\$ 14,500$ to $\$ 10,7409$ because of the $35 \%$ capacity increase (see Figure 26 ). The combined costs are thus $\$ 20,740 /$ month, which means that this option is more expensive. We believe that the optimum VOC concentration between the membrane system and the carbon canisters is about $10 \mathrm{ppmv}$.

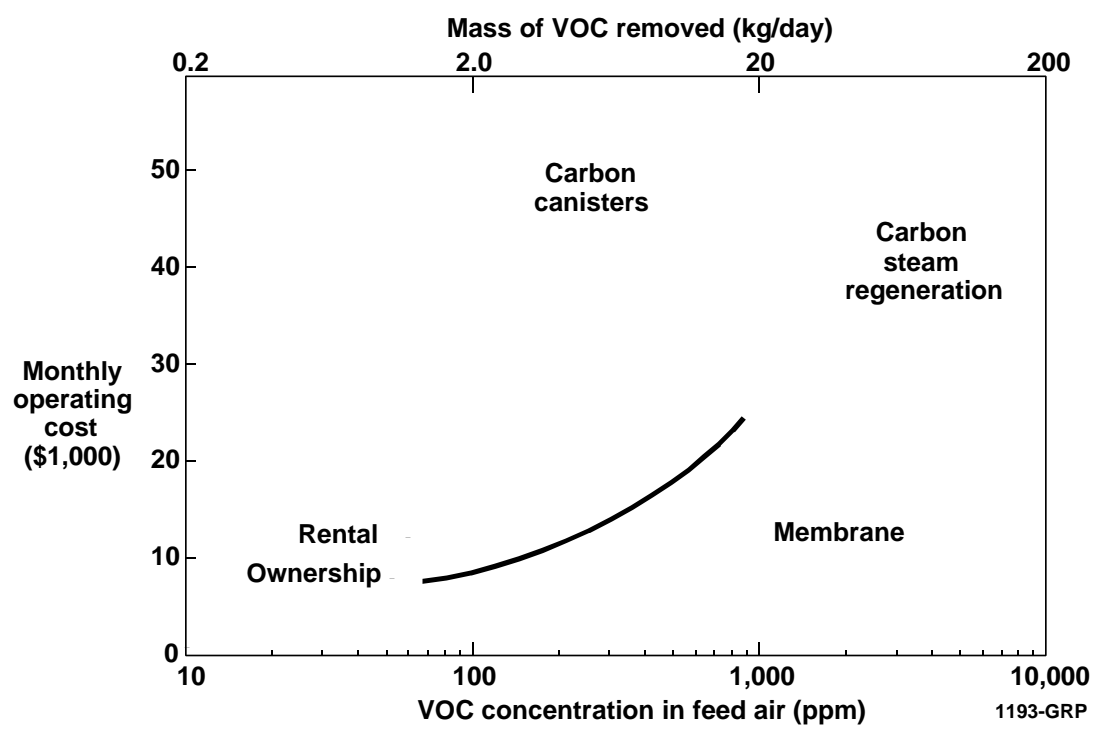

Figure 4. Monthly operation costs as a function of VOC concentration in a 100-scfm air stream for carbon systems and membrane systems.

\subsection{Sequential Use of Membranes and Carbon Canisters}

In many situations, a combination of a membrane system with carbon canisters may be the preferred approach. For example, Figure 28 illustrates the VOC concentration in the off-gas from a typical soil remediation project as a function of time. For the first 100 days of remediation, the VOC concentration is more than $100 \mathrm{ppmv}$, so a membrane system is preferred. Almost $60 \%$ of the total VOC removed during the project would be removed during this period. Thereafter, a simple, low-cost carbon canister system would be used, as the VOC concentration declines from $100 \mathrm{ppmv}$ to below 2 ppmv. The membrane system would be moved to a new site, spreading the capital cost of the unit over several projects. The small size and transportability of the system, and its ability to treat a broad range of VOC concentrations makes this a viable approach. 

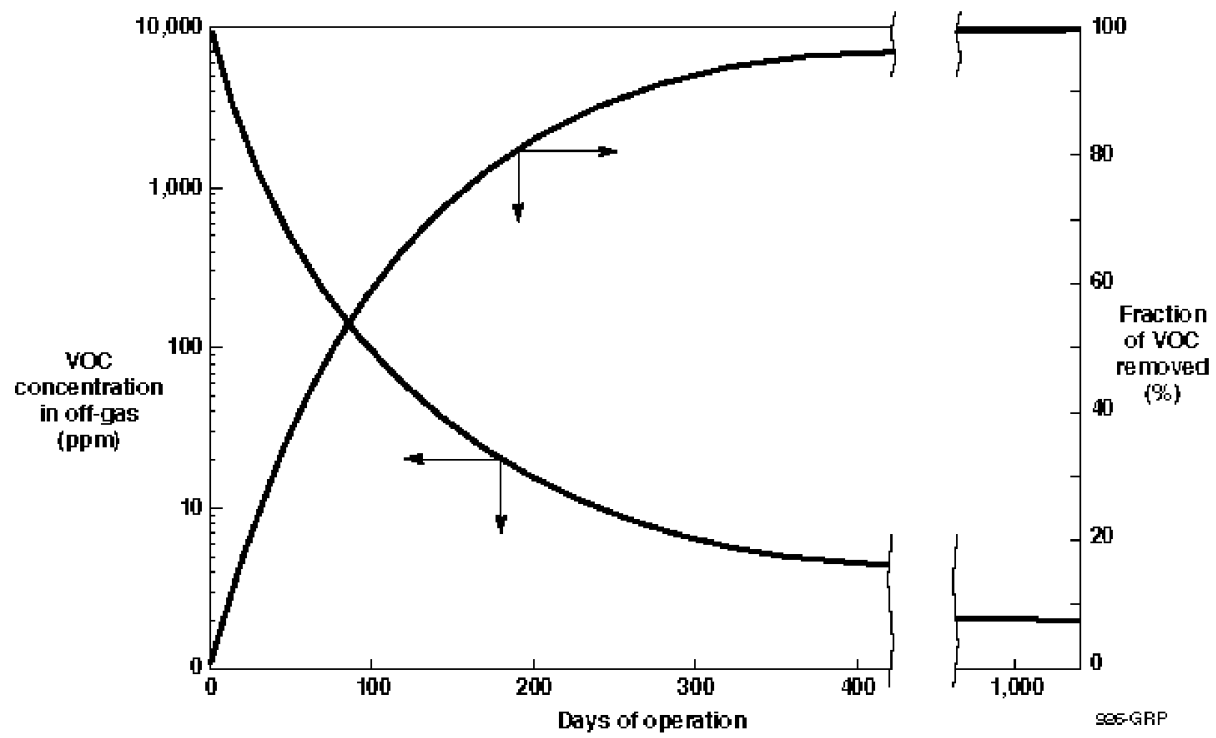

Figure 5. VOC concentration in the off-gas produced by a soil vacuum extraction remediation operation as a function of time. Most of the VOC is removed in the first few months of operation as a relatively concentrated gas. During this period, a membrane system would be used. When the VOC concentration drops to about $100 \mathrm{ppm}$ or less, carbon canisters would be installed.

\section{FIELD SITE SELECTION}

Over fifteen people, mostly part of the DOE complex, were contacted regarding the current project, with the intention of locating field sites for the demonstration system to be constructed in the follow-on phase. A nine-page summary of project objectives and progress to date was prepared and sent to interested parties to provide sufficient information to determine whether the membrane system is applicable to their needs. Two concrete testing opportunities have been identified: one at McClellan Air Force Base and one at the DOE Paducah site in Kentucky. A summary of the status of the contacts is given below. 


\section{McClellan Air Force Base, Sacramento, California}

Contact: Mr. Phil Mook

McClellan AFB is the National Environmental Technology Test Site of the military for vapor-phase VOC treatment technologies. Several remediation activities at the site produce air streams with VOC concentrations in excess of 1,000 ppmv. The main VOC present is TCE. According to Mr. Mook, new vacuum extraction and two-phase extraction wells will be started in the near future, with initial VOC concentrations expected to be very high. The site has an ongoing test program; six different technologies have been evaluated so far. The MTR membrane system was accepted into the test program on April 9, 1997.

\section{Paducah, Kentucky}

Contact: Mr. Walt Richards

Currently only running an air stripper; the air contains 50 ppmv or less TCE. A soil venting system will be installed 18 months from now. The vent is expected to contain 5,000 ppmv TCE, and is a good candidate for a second test (possibly after McClellan).

\section{Hanford Reservation, Washington}

Contact: Mr. Steve Stein

This is the site where MTR performed its first demonstration in 1992. The test was coordinated at that time by the Westinghouse Hanford Company. Westinghouse is no longer involved with the Hanford site and our contacts from 1992 are no longer available. We are currently working through Steve Stein of the Batelle Seattle Research Center to reach the appropriate operation people at Hanford.

\section{$\underline{\text { Savannah River Site, South Carolina }}$}

Contact: Dr. Dan McCabe

This site has lots of TCE contamination; Dan McCabe is looking for appropriate streams.

\section{Portsmouth, Ohio}

Contact: Mr. Tom Houk

No suitable steams have been identified at this time.

Brookhaven, New York

Contact: Mr. Paul Kalb 
No suitable streams have been identified at this time.

\section{Oak Ridge, Tennessee}

Contact: Mr. Jeff Gilpin, Mr. Drew Diefendorf

No suitable streams have been identified at this time.

\section{CONCLUSIONS}

The work performed in Phase I demonstrated that:

(1) Membrane modules containing feed-side baffles have better VOC/air separation properties than conventional modules.

(2) Hollow fiber contactors are very efficient stripping devices for the removal of VOC from water.

(3) The novel system design developed is capable of reducing the VOC concentration in remediation off-gas to $10 \mathrm{ppmv}$, while producing a concentrated VOC phase and dischargeable water containing less than 1 ppmw VOC.

(4) The membrane system is competitive with carbon adsorption if the VOC concentration in the remediation off-gas is $100 \mathrm{ppv}$ or higher.

A design was prepared for a demonstration system able to treat $100 \mathrm{scfm}$ off-gas, and two field sites have been identified. In the subsequent Phase II we propose to build the system and to install it at the McClellan Air Force Base and the DOE Paducah site in Kentucky for field tests. The detailed Phase II proposal is attached as Volume II.

\section{REFERENCES}

1. G.J. van Amerongen, "Influence of Structure of Elastomers on their Permeability to Gases,” J. Appl. Poly. Sci. 5, 307 (1950).

2. R.M. Barrer, "Permeability in Relation to Viscosity and Structure of Rubber," Trans. Far. Soc. 38, 322 (1942).

3. P. Meares, "The Diffusion of Gases through Polyvinyl Acetate," J. Am. Chem. Soc. 76, (1954).

4. V. Stannett, M. Szwarc, R.L. Bhargave, J.A. Meyer, A.W. Myers and C.E. Rogers, "Permeability of Plastic Films and Coated Paper to Gases and Vapors," Tappi Monograph Series, No. 23 (1962). 
5. A.S. Michaels, W.R. Vieth and J.A. Barrie, "Diffusion of Gases in Polyethylene Terephthalate," J. Appl. Phys. 34, 13 (1963).

6. S.A. Stern and H.L. Frisch, "The Selective Permeation of Gases Through Polymers," Ann. Rev. Mater. Sci. 11, 523 (1981).

7. V.T. Stannett, W.J. Chewers, D.R. Paul, H.K. Lonsdale and R. W. Baker, "Recent Advances in Membrane Science and Technology," Adv. Poly. Sci. 32, 71 (1979).

8. S.L. Matson, J. Lopez and J.A. Quinn, "Separation of Gases with Synthetic Membranes," Chem. Eng. Sci. 38, 503 (1983).

9. S. Loeb and S. Sourirajan, "Sea Water Demineralization by Means of an Osmotic Membrane," ACS Advances in Chemistry Series 38, 117 (1963).

10. L.T. Rozelle, J.E. Cadotte, K.E. Cobian and C.V. Kopp, "Nonpolysaccharide Membranes for Reverse Osmosis: NS-100 Membranes," in Reverse Osmosis and Synthetic Membranes, W. Sourirajan, Ed., National Research Council of Canada, Ottawa (1977).

11. C.V. King and J. Kaschemekat, "Volatile Organic Carbon/Air Separation Test Using Gas Membranes," Westinghouse Hanford Company Report to DOE Office of Technology and Development under contract DE-AC06-87RL10930, (August 1993).

12. FY 1993 Program Summary, U.S. Department of Energy Office of Environmental Restoration and Waste Management, Office of Technology Development, DOE/EM0109P, (February 1994).

13. Chemical Week (August 18, 1993).

14. "Purus A2000: A Significant Advance in VOC Removal Technology," Purus Company Brochure, (1994). 